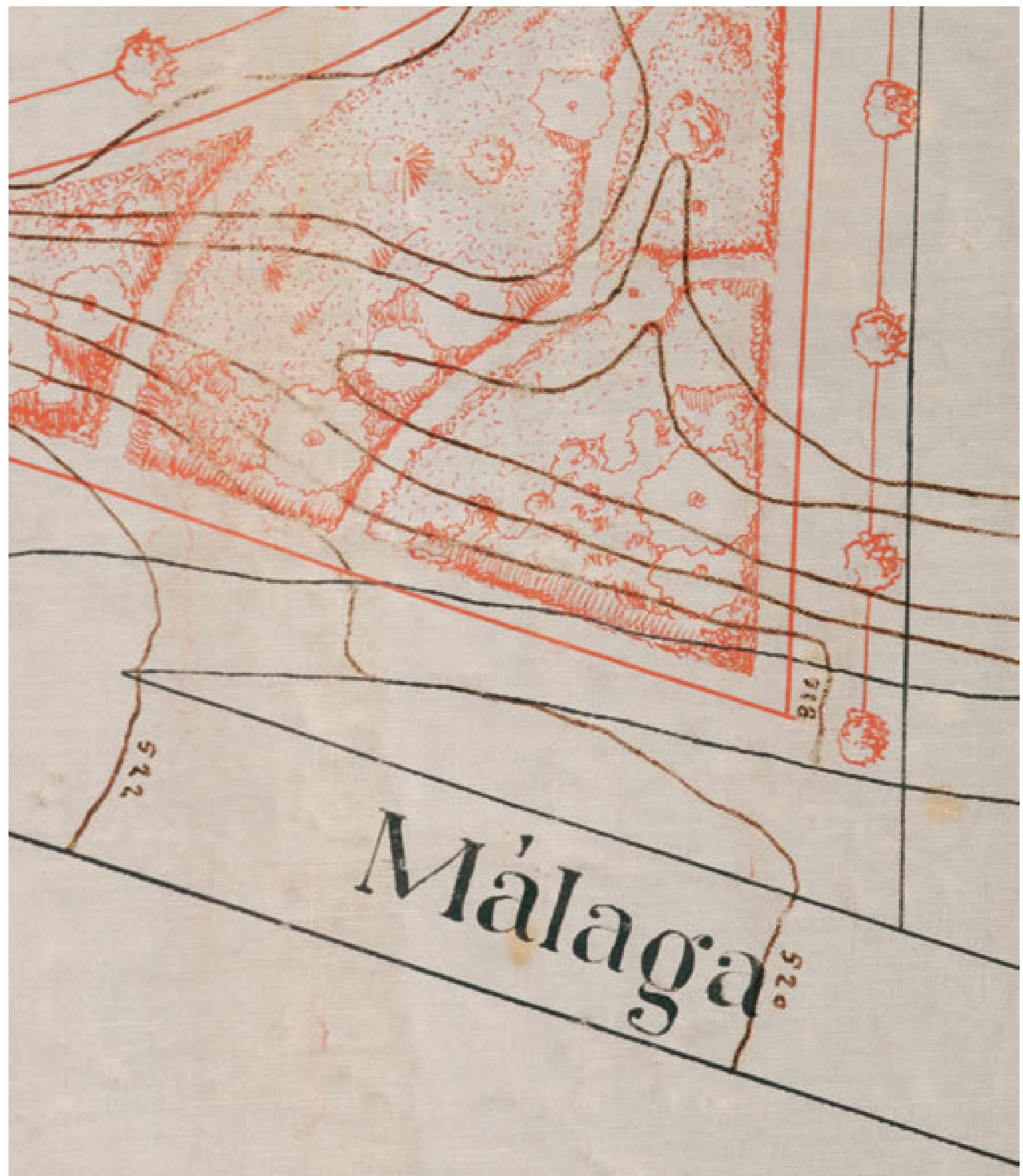




\section{Ciudad y documento. Restauración del plano original del Ensanche de Jaén de Luis Berges (1927)}

Rocío Hermosín Miranda, María Campoy Naranjo, Centro de Intervención del IAPH. Plácido González Martínez, Centro de Documentación y Estudios del IAPH
Detalle de la zona inferior central del plano antes de la intervención. Foto: Eugenio Fernández Ruiz, IAPH

\section{Resumen}

Entre los proyectos de conservación-restauración acometidos por el Taller de Patrimonio Documental y Bibliográfico del IAPH destaca la recuperación del Plano Original del Ensanche de Jaén (1927), sin duda uno de los proyectos más ambiciosos aunque con menos fortuna del arquitecto Luis Berges (18911939). Durante la intervención se debió solventar, además de los problemas derivados de su deficiente estado de conservación, aquéllos relativos a la complejidad del soporte material y la problemática inherente a los documentos de gran formato. Los acontecimientos que rodearon la gestación del ensanche y el contexto histórico en el que se desarrolló el proyecto, los aspectos concernientes al estado de conservación del plano y los tratamientos de intervención experimentales aplicados son algunos de los temas que se abordan en el presente artículo.

\section{Palabras clave}

Berges, Luis / Centro de Intervención / Conservación / Ensanche de Jaén / Instituto Andaluz del Patrimonio Histórico / Intervención / Jaén / Metodologia / Papel / Patrimonio documental / Planos / Restauración / Tela / 1927 


\section{LA CIUDAD}

"... ¿no es un hecho, que a través de la electricidad el mundo material se ha convertido en un gran nervio, vibrando en miles de millas en un punto de tiempo sin aliento? ¡Más aún, el globo es una vasta cabeza, un cerebro, instinto con inteligencia! 0, podriamos decir, es en sí un pensamiento, nada más que pensamiento, y no más la sustancia que creiamos..." (HAWTHORNE, 1851: 283)

\section{La Ciudad Capital}

Las palabras de Nathaniel Hawthorne en 1851 son explicativas del asombro que embargaba a las sociedades occidentales en plena efervescencia de la Revolución Industrial. Gracias a los logros del positivismo, la desaparición de las barreras entre ciudad y campo, de las fronteras que separaban naciones, era una promesa utópica presta a cumplirse en el futuro, que obligaba a despojarse del lastre insoportable de la nostalgia, incompatible con la esencia de una civilización felizmente condenada al movimiento perpetuo.

Un acercamiento a los modos contemporáneos de producción de ciudad es indisociable de la ascendencia de los procesos económicos, sociales y políticos que marcaron el siglo XIX, que hemos de valorar en su justa medida atendiendo no sólo a sus logros, sino también a sus carencias, que motivaron una intensificación de los esfuerzos de progreso y mejora. En ellos hemos de encuadrar toda una serie de actuaciones que, desde la gran escala, buscaron la adecuación de las ciudades al proceso de concentración política y económica que hizo de ellas nodos privilegiados, de fuerza de atracción irresistible, que han sido recientemente caracterizados bajo la denominación genérica de la Ciudad Capital.

Como indicó Ignasi Solá-Morales, la definición de Ciudad Capital tiene una doble vertiente que hemos de considerar de enorme importancia para toda descripción de las sociedades urbanas occidentales: capitalidad, en primer lugar, por la concentración, efectiva y simbólica, de poder político en las ciudades, especialmente al amparo del auge de los Estados nacionales acontecido a lo largo del siglo XIX. Un proceso que, además de plasmarse de manera inmediata en las grandes metrópolis, terminó haciéndose extensivo al conjunto de la sustancia urbana, por la necesidad de expresar espacialmente y arquitectónicamente, hasta el grano más fino, las nuevas organizaciones administrativas estatales surgidas tras la Revolución Francesa.

En segundo lugar, la capitalidad expresaba para las ciudades, según Solá-Morales, un nivel de concentración más dificilmente aprehensible, pero no por ello menos poderoso: el de la economía, el del capital fluido cuya abstracción se encargaba de criticar Marx, que motivaba la confluencia de medios de producción, tecnología, población y cultura en las ciudades como puntos privilegiados del territorio, y que se manifestaba en la mayor de sus grandezas con la escala colosal de las factorias y con la mayor de las miserias en la degradación de las condiciones de vida de sus clases más modestas.

Esta doble condición de capitalidad determina la adopción de dos estrategias de diferente índole con relación a la ciudad, que bien apostaban en mayor medida por el reforzamiento de su carácter simbólico desde una perspectiva artística, o bien incidian, con pleno espíritu positivista, en las mejoras necesarias para su adecuación a los modos de producción propios de la industria. Ante todo, la necesidad de eficiencia en la organización urbana era vista como una necesidad perentoria para los impulsores de estas estrategias, lo que les llevaba a adoptar una actitud frecuentemente falta de escrúpulos a la hora de intervenir en la ciudad histórica. Los viejos trazados urbanos eran campo abonado para el florecimiento de la marginalidad social y la delincuencia, lo que proporcionaba una razón suficiente para que, desde una visión higienista, fuesen privados de todo valor patrimonial para ser considerados como infraestructuras obsoletas, organismos enfermos en manos de facultativos con declaradas inclinaciones a la mutilación y la extirpación, que sólo en casos excepcionales se inclinaban por la medidas preventivas o cuidados paliativos.

La primera de estas dos estrategias es la que procuraba, desde una perspectiva del todo preurbanistica y formalmente conservadora, fomentar la expresión simbólica del poder estatal, que se ejemplifica en la monumentalización de la ciudad, tal vez con la falsa esperanza que la construcción de hitos ofreciese referencias a las que asirse en un contexto de cambio acelerado e imprevisible. Dos actuaciones son generalmente señaladas a su vez como ejemplares de esta perspectiva, y sobre ellas nos detendremos brevemente pues consideramos que, a pesar de constituir referencias caducas para un urbanismo moderno, sí mantuvieron a lo largo del siglo XIX y buena parte del XX un considerable poder de atracción: la intervención del barón Haussmann en Paris y la transformación del Ring de Viena.

Ambas representan actitudes completamente diferentes hacia la ciudad histórica. Por un lado, Haussmann ofreció la demostración de cómo, a través de la aplicación de la táctica del percement, era posible desventrar una ciudad disfuncional y caduca como la vieja capital de Francia. Bajo la piqueta implacable del Prefecto del Sena, el viejo tejido medieval de París fue sucumbiendo desde 1851 a los dictados de la movilidad, la higiene y el control social, que regularizaron su materia y espíritu hasta convertirla en la Ciudad de la Luz'.

En la misma línea "artistica", aunque con diferente actitud frente a la ciudad histórica, se encontraba el caso de Viena, donde la obsolescencia de la infraestructura defensiva de las murallas y el glacis, que en otros tiempos garantizaron la seguridad necesaria para la pervivencia de lo urbano, derivó en la creación a partir de 1857 de un anillo de espacios libres, parques y edificios públicos conocido como el Ring, que servia de escenario para expresar las nuevas conquistas de lo verde para el higienismo, y de la monumentalidad para la cultura, la política y la burocracia (imagen 1). 


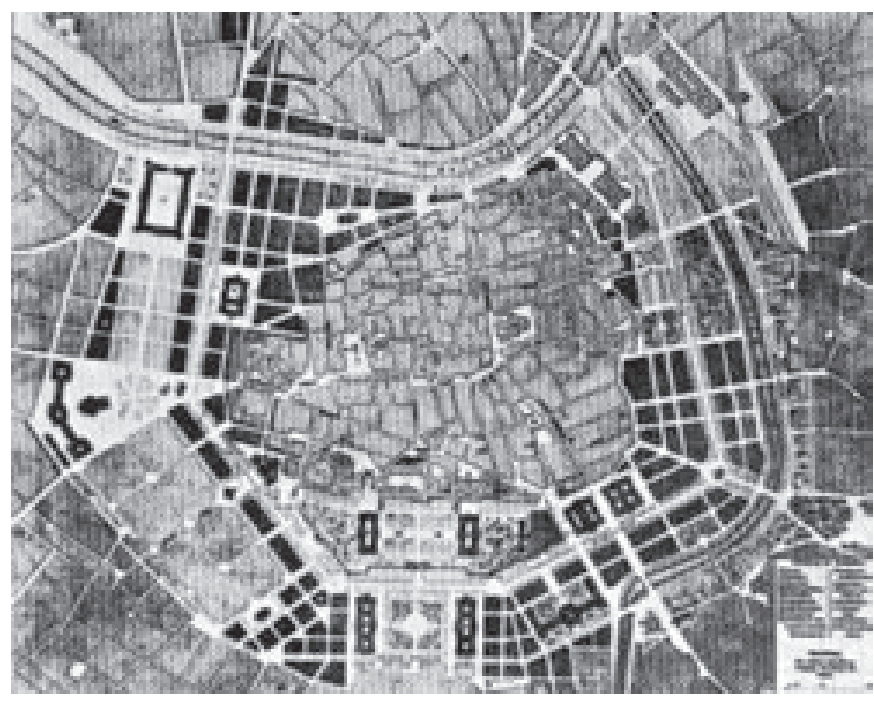

1. Ordenación definitiva del Ring de Viena (1857), tras su reelaboración por parte del Gobierno Imperial. Fuente: SICA, P. Historia del urbanismo. El siglo XIX Madrid: Instituto de Estudios de Administración Local, 1981

Sin embargo, no todo fueron parabienes: París fue denunciada por autores como Michel Foucault como un eficiente dispositivo de control panóptico; mientras que el Ring vienés, lejos de constituirse en elemento integrador, contribuyó a polarizar socialmente la ciudad, sumergiendo a la monarquía austrohúngara en una cápsula aséptica desde cuyo interior no pudo prever su ruina. Paris y Viena sirven por tanto de ejemplos cualificados de una manera de entender la nueva capitalidad de la metrópolis industrial desde el monumentalismo, un enfoque que consiguió prevalecer de forma paradójica y cobrar especial vigor en el cambio de siglo en los Estados Unidos de América bajo la denominación de City Beauti$f u l^{2}$. Pero como hemos indicado, existía una segunda estrategia, la guiada por el positivismo, que buscaba la convergencia entre producción de ciudad y los modos de producción industrial, en la que hemos de situar a los planes de ensanche, y en concreto, a la figura de Ildefonso Cerdá y a su plan para Barcelona, como sus ejemplos más destacados.

\section{Expansión urbana versus desarrollo urbano. Ciudades y ensanches}

El ensanche nos plantea una cuestión, como es el esfuerzo por encauzar el gigantismo de la ciudad, que da pie a incidir en la distinción fundamental existente entre expansión urbana y desarrollo urbano, y en la que el ensanche planteaba una aportación fundamental: la expansión, entendida como aumento del volumen de una actividad, se traducía en ámbitos geográficos tan separados como la ciudad de Nueva York con el plan de los Commissioners de $1811^{3}$ o en el Berlín de los Mietskaserne de finales del mismo siglo (imagen 2), como la repetición invariable de trazados y tipologías que daban como resultado ciudades indiferenciadas e indiferentes, espoleadas exclusivamente por la especulación inmobiliaria sin cuestionarse en momento alguno si resultaban idóneas o no para ofrecer una respuesta a las nuevas exigencias de la eficiencia, productividad y salubridad. El desarrollo urbano, del

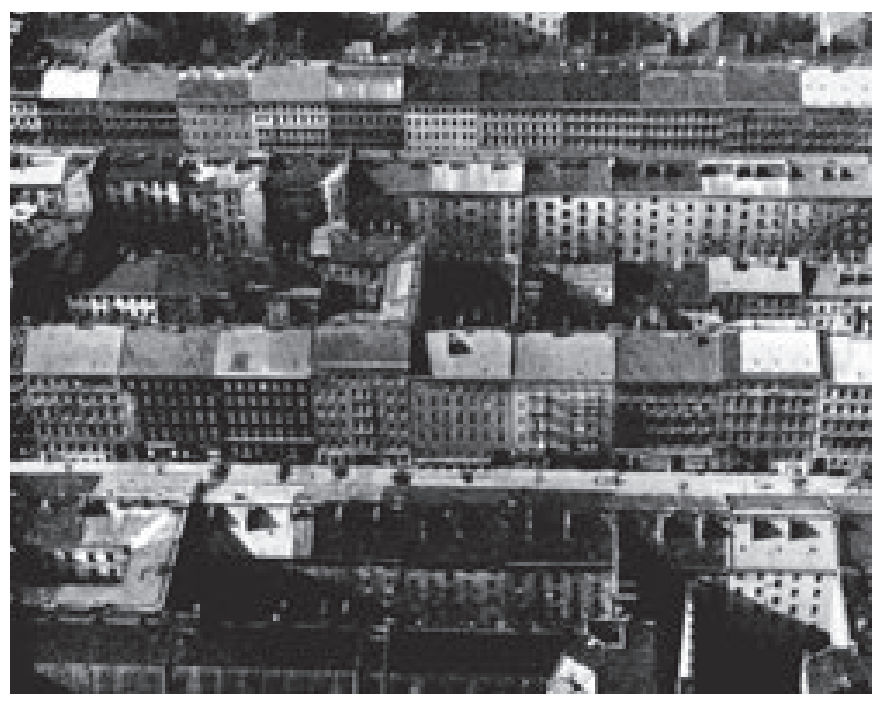

2. Mietskaserne en Berlín. Imagen aérea de la primera década del XX. Fuente: HALL, P. Ciudades del mañana. Historia del urbanismo en el siglo XX. Barcelona: Ediciones del Serbal, 1996 (Oxford, 1988)

que el ensanche sirve de ejemplo, implicaba la introducción de las ideas de diferenciación y de organización, que desde el Darwinismo ya llevaban implícito el concepto de evolución: diferenciación, para proponer la necesaria especialización del tejido urbano según funciones; y organización, para promover su accionamiento coordinado y conjunto, a la manera del funcionamiento de un ser vivo o una máquina.

Organizada de esta manera, la metrópolis industrial habría de ofrecer una cumplida respuesta a su nueva condición de Ciudad Capital que obligaba a un esfuerzo por el desarrollo, no por la mera expansión, y ahí es donde se producia el progreso, la conciencia de avance: si bien las operaciones de embellecimiento y decoro urbano formaban parte de las estrategias comunes de las que el poder político, económico y religioso habian hecho uso a lo largo de la historia, la necesidad de dar respuesta eficiente a su nueva condición de herramientas del capital económico e industrial obligaba a la adopción de nuevos modos de hacer. La necesidad de converger hacia la eficiencia reconocida del mundo de la industria conducía hacia un entendimiento de la intervención urbana completamente volcado hacia la abstracción, el cálculo y la normalización, que ya habremos de situar en la antesala de la modernidad.

Los primeros planes de ensanche suponen el triunfo del pragmatismo en la organización urbana, de una nueva racionalidad aplicada a la construcción del hábitat humano basada en dos aspectos fundamentales: la confianza en el positivismo y la técnica para resolver la complejidad de los problemas urbanos, y la voluntad de establecer una separación clara entre lo público y lo privado en los procesos de construcción de la ciudad, que garantizasen a la propiedad privada, como principal agente económico en el sistema del laissez faire, la máxima libertad de iniciativa, en un marco que garantizase la máxima eficiencia en la provisión de servicios. 
Tales propósitos se hacian posibles gracias a la intervención del Estado que, despojándose de los uniformes de fiesta con que le vestía el eclecticismo y el entendimiento monumental de la intervención urbana que hemos descrito en París y Viena, manifestaba su poder de manera más cruda, a través del reforzamiento de su capacidad de expropiación y del establecimiento de límites a la actividad privada a través de la redacción de ordenanzas, que garantizasen tanto la coherencia y la paz del proceso de construcción urbana, como el mantenimiento del valor económico de las propiedades. A través de estas manifestaciones coercitivas, el poder estatal se mostraba de una manera latente, no evidente, y de la misma manera se plasmaba el valor contemporáneo de la construcción urbana, que dejaba de radicar en la forma, para instalarse en el proyecto: declaración de intenciones y establecimiento de directrices que acompañasen el desarrollo urbano; entendido éste como proceso racionalizable capaz de ofrecer el tablero en el que desarrollase el juego de las fuerzas vivas de la economía capitalista.

\section{Barcelona como paradigma}

En contra de lo que se pueda pensar hoy dia, desde una asunción completa de sus bondades, el ensanche, entendido como exponente avanzado de esta racionalización, era visto durante la segunda mitad del siglo XIX como un modo de producción de ciudad frío y abstracto, sin sentimientos ni memoria, opuesto a la calidez que ofrecía la ciudad histórica, en vías de desaparición. Sin embargo, el ensanche daba, desde una perspectiva progresista, la posibilidad de plasmar los principios de isotropia, igualdad y desaparición de las jerarquias que caracterizaban al nuevo orden social, que se proyectaba en esta manifestación construida con plena confianza utópica en sus principios regeneradores. Ésta era la intención última de Cerdá, ofrecer una alternativa a la degradación de la ciudad histórica, a su altura, densidad, a su congestión, resumible en el lema que hizo famoso: urbanizar el campo, ruralizar la ciudad.

El ensanche de la ciudad de Barcelona habria de ofrecer una respuesta eficiente a dos cuestiones principales: la necesidad de vivienda salubre y descanso que demandaba una población hasta 1854 encerrada tras el cerco implacable de sus murallas, y la adecuación que requerian los nuevos medios públicos de transporte, con el tranvía y el ferrocarril como protagonistas absolutos. Para este reto, el ensanche acudía a una morfología asociada a lo largo de la historia a procesos de elevada intensidad de desarrollo urbano y económico, como era la retícula; un sistema que se mostraba completamente adecuado a las necesidades y requerimientos de la economía capitalista: la división en una malla cuadrangular perpendicular transformaba las tierras alrededor de la capital en suelos, de la manera más sencilla y eficiente.

La malla se ofrecía como soporte para la sistematización de la construcción urbana; que no requería de la invención, del in- genio o del arte del arquitecto, sino de la simple adecuación de elementos generalizables por su acuerdo con el contenedor capaz, la manzana de 100 metros de lado. En el interior de la malla, todo cabía: desde los edificios lineales de viviendas que Cerdá colocaba inicialmente aisladas en dos lados de la manzana, hasta la arquitectura especulativa de los arquitectos del Noucentisme, una plaza de toros o la Sagrada Familia de Antoni Gaudi. La estructura primaba sobre el capricho, reflejando el esquematismo de la organización de la nueva sociedad. La propia aproximación documental al ensanche de Cerdá muestra su sencillez como procedimiento; solamente era necesaria la definición de un módulo, su adecuación a unos ejes, y la definición de tres cotas: la existente del terreno, la modificada, y la cota de saneamiento, para llevar a cabo su desarrollo virtualmente ilimitado (imagen 3).

Puede que lo implacable y rotundo de la malla terminase ofreciendo una imagen más cercana a la expansión que al desarrollo, prevaleciendo sobre la variedad de aspectos y sutilezas que Cerdá procuró para su nueva ordenación, de manera especial por el cuidado en las conexiones de la trama a la ciudad preexistente. Pero entre esas sutilezas encontramos la razón de ser de su conciencia de desarrollo; lo que podriamos Ilamar la "sal y pimienta" del plan, que llegaba por la atención al establecimiento de una nueva jerarquía, resultado de un principio de construcción incremental de indudable rigor, a cuyos escalones se iban asociando diferentes niveles de provisión de equipamientos que garantizasen el equilibrio y la homogeneidad. Cada veinticinco manzanas, que constituian la unidad mínima del barrio, se preveía la construcción de un centro social; cada cuatro barrios, se garantizaba la provisión de un mercado; cada ocho barrios, un parque; y cada dieciséis, un hospital. A través del ensanche, la ciudad trascendia su asociación al capital para servir de soporte a la construcción cohesionada de la sociedad.

El pensamiento avanzado que subyacía en el proyecto de ensanche para Barcelona de Ildefonso Cerdá ha quedado situado en la historia del urbanismo como un momento cumbre de la planificación y diferentes autores discuten acerca de la paternidad del urbanismo como disciplina entre el propio Cerdá y los teóricos alemanes como Baumeister y Stübben que, de manera más tardía, elaboraron un corpus teórico cuyo espiritu científico se considera ya en la antesala de la planificación moderna. Estas consideraciones aparte, sí es un hecho que el ensanche se convirtió en un paradigma del desarrollo urbano en las principales capitales de nuestro país, que en la línea avanzada por Cerdá, confiaron en la posibilidad de racionalizar su expansión, de introducir elementos cualitativos por encima de los meramente cuantitativos. Madrid, Bilbao, Valencia, San Sebastián... se dotaron en pocos años de sus propios planes de ensanche, en una tendencia que quedaría legitimada con la aprobación en 1864 de la primera Ley de Ensanches, que tras su actualización en 1876 desembocó en la ley de 1892, a la que se acogerían las principales capitales, y entre ellas, la ciudad de Jaén. 
Localizamos los ensanches dentro de una línea positivista que, no obstante, estuvo expuesta al predicamento que seguía manteniendo la perspectiva monumentalista de la City Beautiful, que tendió a adornar de embellecimiento urbano una actitud originariamente sobria, concisa y científica. Este cometido de racionalidad comenzaba a avanzar por otros derroteros, ya que a partir del cambio de siglo, y bajo la influencia de nuevas propuestas como la Garden City de Ebenezer Howard (1898) (imagen 4) y la Cité Industrielle de Tony Garnier (1917), el mismo progreso tecnológico que habia hecho posible la aparición del ensanche como modelo avanzado de organización urbana puso en crisis su vigencia. La organización empresarial del laissez faire daba paso a la concentración monopolista, y los medios de producción de la industria tomaban ejemplo de la experiencia de Henry Ford en los Estados Unidos para organizar la producción en cadena, simplificando procesos y optimizando costes.

La arquitectura y el urbanismo modernos contemplaron la posibilidad de convertirse por si mismas en generadoras del cambio, y no en meras acompañantes, a través de la apuesta, nada sutil, por la eugenesia urbana. Es éste el contexto en el que se entienden las polémicas invectivas de Le Corbusier contra la ciudad densa, y que en el primer tercio del siglo XX replanteaban la actualidad de las propuestas de ensanche del siglo precedente, que si bien desde la vanguardia arquitectónica y urbanística ya dejaban de ser consideradas válidas para el desarrollo de las grandes metrópolis industriales, sí seguian disfrutando, especialmente en ciudades medias, de un cierto predicamento, cuyos restos podemos localizar todavía, expuestos a merced de las cada vez más poderosas corrientes del cambio. La fecha de 1927, en que Luis Berges elabora el plano del ensanche de la ciudad de Jaén, puede ser considerada, por tanto, como fecha de transición, equidistante entre dos proyectos claves de Le Corbusier, como son la Ville Contemporaine (1922), en la que seguía apareciendo la tipología de manzana cerrada propia del ensanche de los Inmuebles Villas en cuartel, y la Ville Radieuse (1935), que en su famosa lámina VR-8 declaraba la muerte de la manzana cerrada para encumbrar a la edificación abierta, al bloque à redent, como su legítimo sucesor (imagen 5).

Como testimonios de este clima de transición habremos de destacar el valor de planes de ensanche como el de Jaén, producidos en momentos de cambio cuya trascendencia sólo fue posible aprehender con el paso de los años, cuando tras la caída de las bombas en España y en Europa, abriéndose paso a través de la "tabula" rasa de la guerra, el urbanismo moderno comenzase a proclamar sus promesas, no siempre cumplidas, de redención para la ciudad.

\section{El Proyecto del Ensanche de Jaén ${ }^{4}$}

Jaén hereda en el siglo XX un núcleo urbano demográfico y constructivamente hacinado en torno a la antigua muralla, fruto de la desidia y la falta de estrategias de planeamiento urbanístico de los poderes municipales.

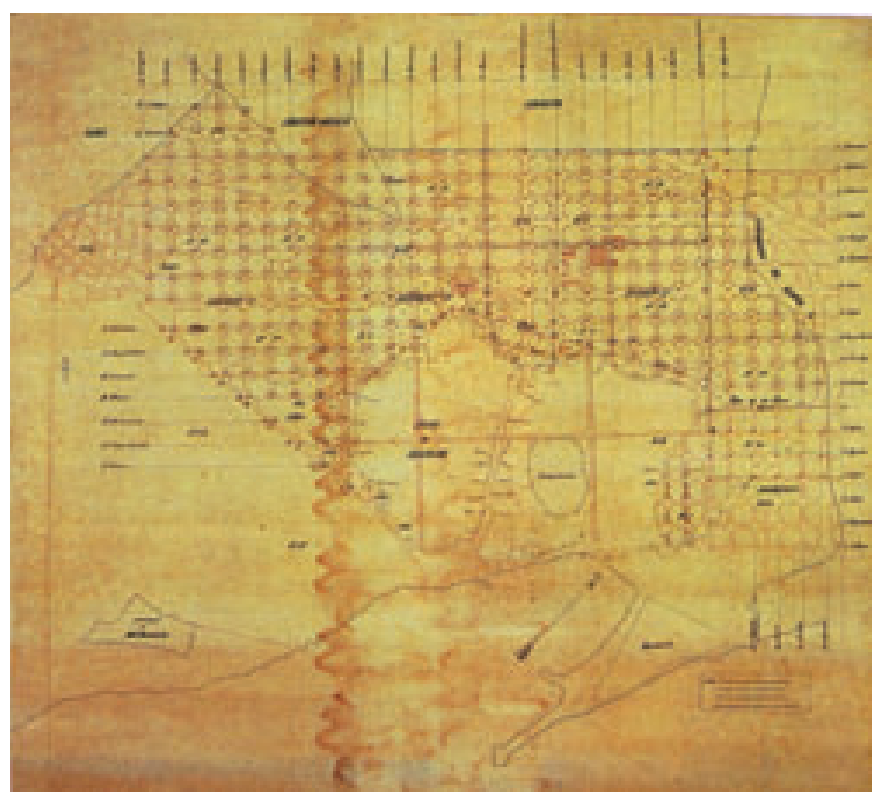

3. Plano geométrico del Ensanche de Barcelona construido, con indicación de las cotas de saneamiento, alineaciones y nomenclatura de calles. Josep Fonteré, c. 1865. Fuente: AA.W. 1856-1999 Contemporary Barcelona Contemporània. Barcelona: CCCB, Diputació de Barcelona, 1996

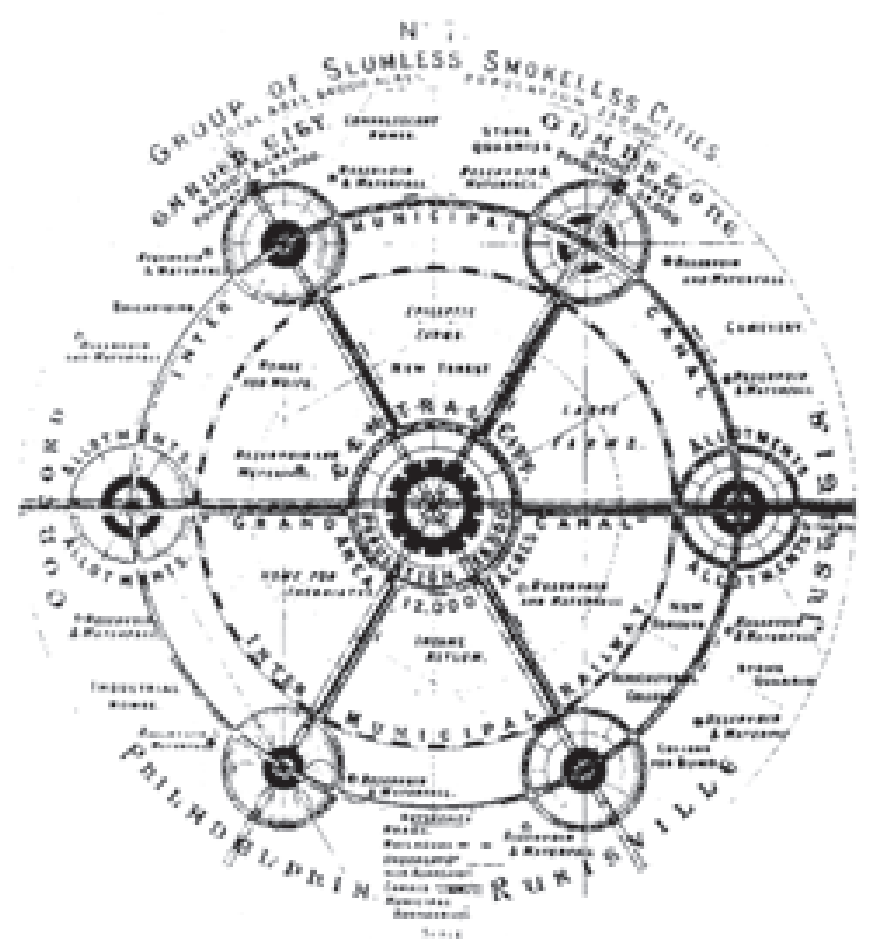

4. Planta de la Ciudad Jardín (1898) de Ebenezer Howard. Fuente: HOWARD, E. Garden Cities of To-Morrow. Cambridge (Mass.): The MIT Press, 1965 (London, 1902)

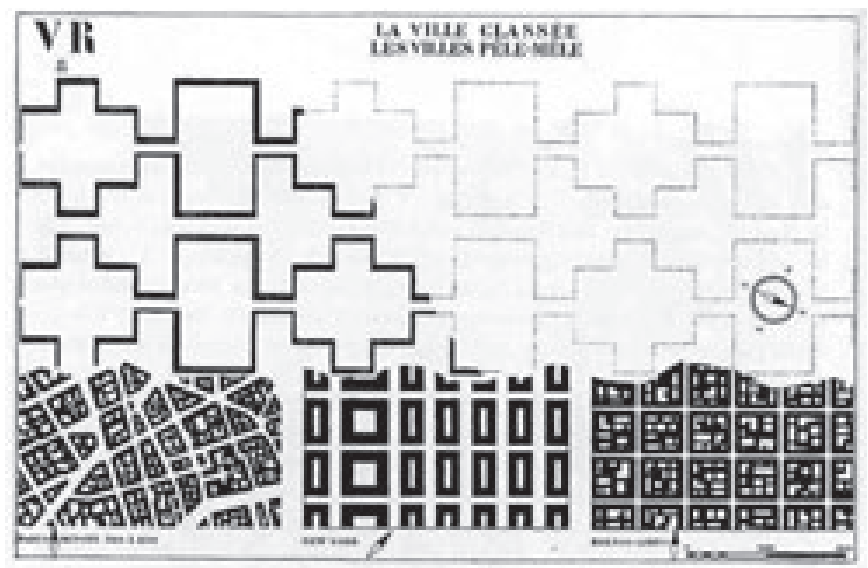

5. Lámina VR-8 de la Ville Radieuse (1935) de Le Corbusier. Fuente: MONTEYS, X. La gran máquina. La ciudad en Le Corbusier. Barcelona: Ediciones del Serbal, 1999 
La primera iniciativa firme del Ayuntamiento de Jaén en materia urbanística se remonta a 1922 a raiz de la gestión de un expediente para obtener del gobierno los beneficios de la Ley de Ensanches de Poblaciones de 1892, con vistas a la expansión del núcleo urbano hacia el norte, consecuencia de la construcción de la línea ferroviaria Linares-Puente Genil.

En el verano de 1923 la Comisión de Gobierno Interior del Ayuntamiento redactaba el Proyecto de Reglamento para el Régimen Interior de la Comisión de Ensanche, de conformidad con lo dispuesto en la Real Orden de 18 de mayo del mismo año, que concedió a Jaén los beneficios de la Ley de 26 de julio de 1892, proyecto que se remitió aquel mismo mes al Ministerio de la Gobernación para su aprobación definitiva.

Por fin, el 7 de julio de 1923 el consistorio encargaba al arquitecto municipal Luis Berges Martínez la redacción del Proyecto de Ensanche y Plano General de la ciudad.

Para su elaboración Berges se basó en el plano topográfico y parcelario propuesto por el anterior arquitecto municipal, Agustín Eyries, levantado por el ayudante de Obras Públicas Miguel Guerrero en octubre de 1922, y en los planos proporcionados por el Instituto Geográfico y Estadístico. No obstante, la falta de datos sobre la red de saneamiento, cuyo proyecto se encontraba en pleno concurso público, obligó a Berges a solicitar una prórroga en el mes de noviembre de 1924. Su renuncia como arquitecto municipal para incorporarse a la Delegación Provincial, sin que la corporación hubiese ratificado el encargo, dejó el proyecto en suspenso.

En 1926, coincidiendo con la celebración del Congreso Nacional de Ciudades de Sevilla, Berges toma la decisión personal de retomar el trabajo, paralizado ante el caos originado entre los propietarios de los terrenos afectados. Propone el antiguo proyecto al Ayuntamiento, que acepta sin mencionar honorarios aunque con firmes promesas de incluirlo en los presupuestos municipales.

La falta de sintonía entre el arquitecto y la corporación municipal es evidente a lo largo de todo el desarrollo del proyecto y, necesariamente, ese desentendimiento se reflejará en la consecución del Ensanche de Jaén.

En abril de 1927 la corporación reclama a Berges la entrega del proyecto en un plazo de un mes cuando tal encargo no se formaliza hasta el 3 de mayo siguiente. Cuando por fin concluye el trabajo en el mes de julio, tropieza con la pasividad del consistorio, optando por entregar el proyecto en el mes de diciembre sin percibir remuneración. En el primer semestre de 1928 la propuesta se expone al público durante un plazo de 60 dias, sin que hubiese reclamación alguna por parte de la ciudadanía; el arquitecto no tiene noticias de la presentación y, por la prensa, se entera de que ha sido aprobada por la corporación municipal.
Ante la evidente falta de voluntad política, el 23 de julio de 1928 comunica por carta su decisión de donar el Proyecto del Ensanche al pueblo de Jaén, manifestando que no renunciaba a la propiedad intelectual del mismo y que en ningún caso podría ser modificado sin su autorización.

En un intento de subsanar el agravio el pleno del Ayuntamiento del 3 de octubre de 1928 ratifica la entrega de 5000 pesetas a cada uno de los colaboradores del proyecto: Luis Berges Martínez como arquitecto, Enrique Martos Carrillo en calidad de ayudante y Jesús López Jiménez por su labor como delineante. Finalmente el Ayuntamiento sólo libra las 5000 pesetas estipuladas en 1923 y Berges renuncia a cobrarlas.

En 1931 la corporación gestiona las obras necesarias para ejecutar el proyecto y un lustro después se abre expediente sobre los terrenos afectados por el Paseo de la Estación. La ejecución del Ensanche se lleva a cabo tras la Guerra Civil, coincidiendo con el año de la muerte de Berges, aunque de tal manera desvirtuado que resulta casi irreconocible.

En Luis Berges se percibe a un arquitecto impar que supo evolucionar su concepción de la arquitectura hasta asumir los postulados racionalistas de las vanguardias europeas. Proyectó numerosos edificios, sobre todo en Jaén, palpitando en ellos "un irrefrenable diseño moderno-funcionalista, que aparece enmarcado por el ropaje del historicismo, quizá en un intento de fundir tendencias dispares" como dice Pérez Escolano (1980: 349-357). Artífice del Pabellón de Jaén en la Exposición Iberoamericana de Sevilla (1929), el Sanatorio del Neveral (1930), la Escuela elemental de Trabajo (1930) o la Casa Almansa (1934), sin duda, su obra más destacada habría sido el Proyecto del Ensanche de Jaén si las circunstancias y acontecimientos del momento no lo hubiesen impedido. No obstante, el Plan Berges fue el modelo condicionante para el posterior crecimiento de Jaén.

\section{EL DOCUMENTO}

El Plano del Ensanche de Jaén es un documento original, firmado y fechado en Jaén el 4 de julio de 1927 por el arquitecto Luis Berges, y aprobado por el pleno del Ayuntamiento el 31 de diciembre sucesivo. Forma parte de la Memoria General del Proyecto del Ensanche de Jaén, conservada incompleta en el Archivo Municipal de la ciudad. Su hallazgo por el propio hijo del arquitecto, el también arquitecto Luis Berges Roldán, y el traspaso de su propiedad al Colegio Oficial de Arquitectos de Jaén, además de su celebrada recuperación material -pues se encontraba en un estado de conservación deficiente fruto de haber permanecido en un medio húmedo muy hostil teniendo en cuenta la naturaleza de este tipo de soporte-, ha suscitado la revisión y valoración de uno de los proyectos más sobresalientes de Luis Berges Martínez, tanto por la envergadura y complejidad de los trabajos, como por la influencia que ejerció en el posterior desarrollo urbanístico de Jaén. 


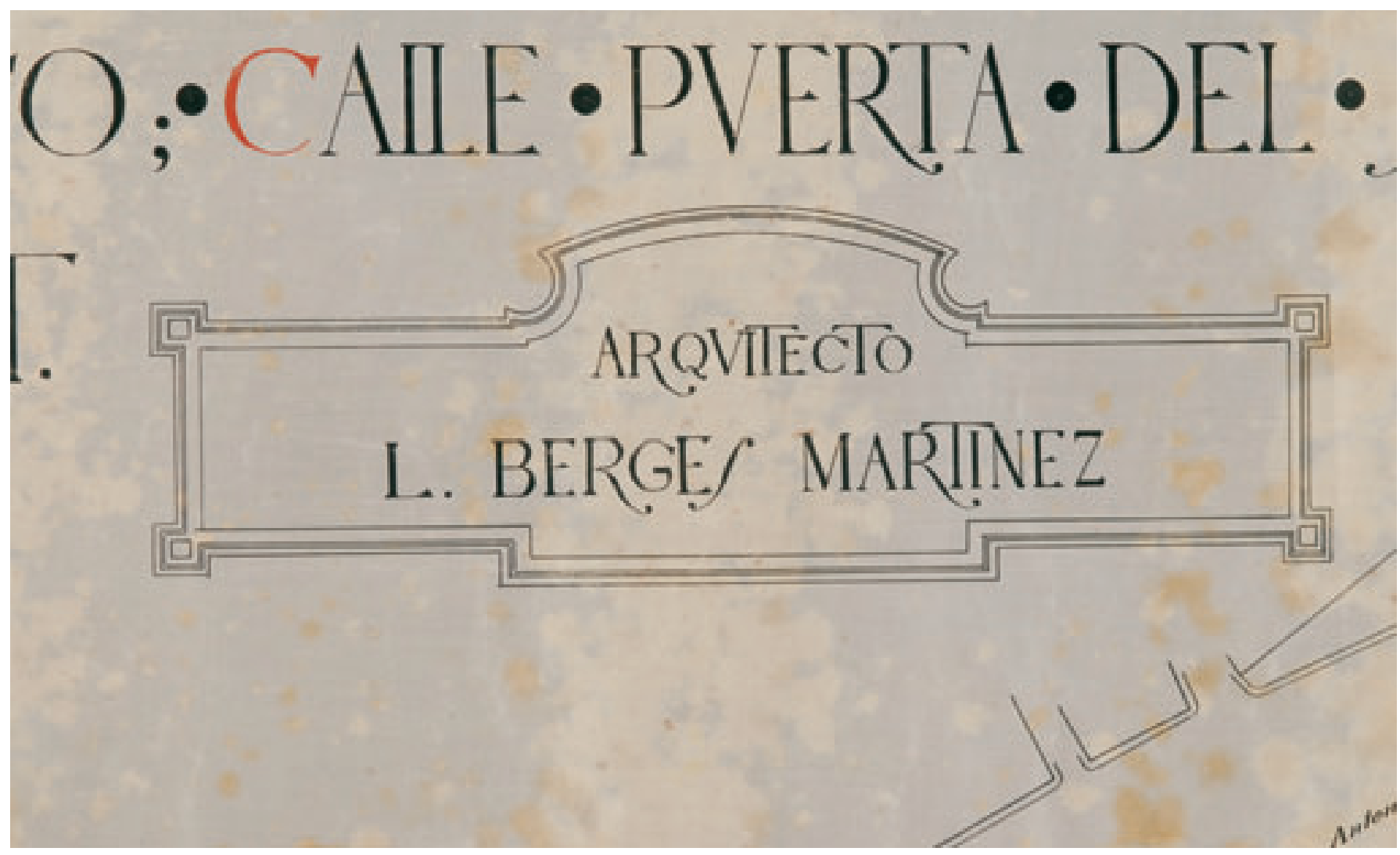

6. Cartela con el nombre del autor del proyecto. Detalle del anverso. Foto: Eugenio Fernández Ruiz, IAPH

\section{Historia material}

La morfología del documento viene definida por su gran formato horizontal de 1400 × 2600 mm y el soporte de fabricación industrial "especial" sobre el cual se trazó la planimetría.

La elección de un formato de esta magnitud, por la dificultad que entraña su manipulación tanto para el restaurador que afronta la intervención, como para el propio técnico arquitecto que debe trabajar sobre el plano, nos inclinan -sin dispensarle en ningún caso de su valor técnico a conferirle un carácter o función expositiva, pues las particularidades morfológicas (dimensiones y elementos gráficos) del documento lo hacen idóneo para presentar visualmente la realidad del proyecto urbanístico que se quiere poner en conocimiento de la ciudadanía.

Aunque no es posible certificar que sea el mapa expuesto en 1928 por el Ayuntamiento para dar a conocer la dimensión del Plan Berges a la sociedad de Jaén, dentro de la mencionada Memoria General del Proyecto, recordemos que incompleta, no se han encontrado documentos con las características morfológicas de la presente planimetria.

A primera vista el plano resulta poco exhaustivo a la hora de reflejar aspectos técnicos y urbanísticos, señalando únicamente ciertos sectores y la orografía del terreno, en la línea manifiesta en otros proyectos de ensanche de la época; en cambio, es detallista en la recreación del arbolado y zonas de recreo, en la identificación de los diferentes edificios públicos y de las áreas destinadas a vivien- da social como las casas baratas y para obreros, y en los límites que marca el área del ensanche.

También con criterio visual se definió el trazado a través de tintas al agua de varios tonos que atienden a un código de colores utilizado por Berges en la mayoria de sus proyectos y que, posiblemente, no tiene más razón de ser que la de facilitar la comprensión de la planimetria sin la necesidad de recurrir a leyendas u otros signos convencionales. En este caso, las tintas negras se destinaron a planificar las áreas existentes previstas preservar; las rojas a las zonas de nueva planta; las amarillas a los espacios edificados a demoler, por lo general superpuestas a las estructuras delineadas en los otros colores. Un último color, el azul, no está presente en el plano que nos ocupa por corresponder a la cerrajería, visualizada en otros proyectos de Berges. Por otra parte, se detectaron tintas en tono pardusco de naturaleza metaloácida para dibujar los escasos caracteres topográficos y el acotamiento presentes en el plano.

No podía faltar en el documento la correspondiente escala de medida y la rosa de los vientos, pero la entidad del proyecto viene marcada por el escudo del Área de Gestión Urbanística del Ayuntamiento de Jaén (blasón cuartelado, $1^{\circ}$ y $4^{\circ}$ de oro, $2^{\circ}$ y $3^{\circ}$ de gules con bordadura componada de Castilla y León en catorce cuarteles, todo sobre escuadra) que encabeza el plano, incluyendo la relación de las áreas geográficas afectadas y la cartela que enmarca el nombre del arquitecto responsable (imagen 6).

Todos los elementos gráficos se ubican en el anverso del soporte, a excepción de un fino rayado a tinta negra en el reverso de la 


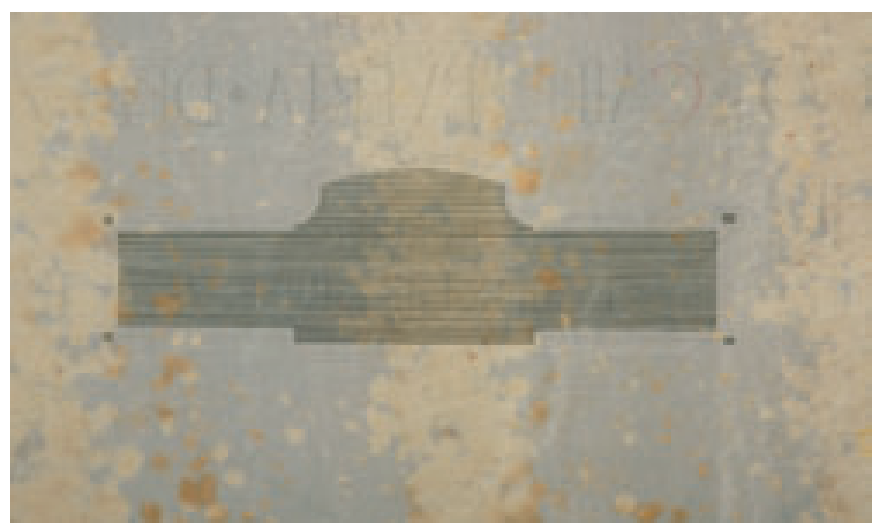

7. Rayado para crear efecto de sombreado en la cartela. Detalle del reverso. Foto: Eugenio Fernández Ruiz, IAPH

cartela del arquitecto. El rayado es un recurso que hemos visto en otros planos de estas características y su función es la de crear un efecto decorativo de sombreado en las áreas que se desean destacar (imagen 7).

Con respecto al tipo de soporte, clasificarlo como "especial" se debe a la rareza de su conjunción; un tejido de fibra de algodón ${ }^{5}$ sin teñir, con ligadura de tafetán ${ }^{6}$, obtenido a partir del tratamiento de apresto de una tela, probablemente con almidón -aunque no ha sido posible discernirlo en los análisis efectuados-, que por su acabado recibe diversas denominaciones: tela de plano, papeltela, tela de calcar, etc.

El proceso de fabricación se realizó a partir de un tejido de algodón de bajísima densidad que, impregnado por ambas caras con un encolante (gelatinas o emulsiones fotoesténicas) para suavizar la fibra y aumentar su flexibilidad y firmeza, prepara la superficie para la mejor aplicación y fijación de las tintas. En este caso concreto se utilizó una emulsión al agua fijada en caliente mediante rodillos giratorios al vapor (denominados calandras) que fijan, prensan y satinan el soporte proporcionándole mayor lisura, flexibilidad, resistencia y planicidad. Este proceso también hace apto al soporte para recibir otras técnicas secas tradicionalmente aplicadas al papel, como el lápiz de grafito.

Entre los factores que explican la abundante documentación de mapas y planos que sobre este tipo de soporte se conserva en archivos y bibliotecas se barajan varias cuestiones. En primer lugar la industria textil permite la fabricación de rollos de tela de unas dimensiones sensiblemente mayores que las del papel, lo cual favorece la ejecución de planos y otros documentos que precisan soportes de mayor formato. También es importante el factor económico pues se abarata considerablemente el coste del soporte al hacer uso de telas de grosores mínimos que requieren poca materia prima para su fabricación.

Por otro lado, el tejido tiene una gran estabilidad química y una mayor resistencia física que el papel de pasta de madera, siendo más difícil su deterioro por causa de plegados o enrollados continuos. $Y$ es que las grandes dimensiones de estos documentos y la escasa calidad del papel de pasta maderera común de la época, muy susceptible de arrugarse, romperse o desgarrarse, además de oscurecerse y volverse quebradizo con el paso del tiempo, hacen que el papel no sea en estos casos el soporte más adecuado. Especialmente delicados son los papeles transparentes o semitransparentes empleados para los calcos de planos (papel vegetal, cristal, al aceite, cebolla, parafinado, encerado, etc.) cuya celulosa, ya muy degradada por su propio sistema de fabricación o algunos de sus aditivos (grasa, parafina, cera, etc.), ocasionan grandes problemas de conservación. También sus propiedades físico-mecánicas como la resistencia a la luz, al calor y los ácidos, prolongan su estabilidad y durabilidad. Este tipo de soporte permite, además, la obtención de cuantas copias sean necesarias utilizando papeles al ferroprusiato o cianotipos ${ }^{7}$

En su contra juega un papel determinante la oxidación, pues provoca que el tejido se torne azul-grisáceo y pierda su transparencia. Todavía más importante y que ha planteado el mayor problema de conservación del Plano del Ensanche de Jaén es su alta sensibilidad en un medio hostil como la humedad y el agua. En este ambiente la gelatina se deshace, provocando la pérdida de la consistencia del soporte y favoreciendo la aparición de cultivos de hongos.

La observación visual de la planimetría permite determinar tres fases de ejecución del dibujo: una inicial de encaje a base de lápiz de grafito, tal vez con ayuda de un boceto preparatorio colocado bajo la tela semitraslúcida para centrar el plano; en segundo lugar la delineación con tiralíneas en tres tonos, trazando en último lugar las áreas en amarillo; y a juzgar por las líneas sobrepuestas al resto de la planimetria, en tercer lugar se procedió a ejecutar la orografía del terreno con tintas metaloácidas.

Una cuarta y última fase correspondería a la rotulación de toda la planimetría, realizada a mano, que imita una tipografía romana actualizada muy en boga durante los años veinte de la pasada centuria por su simbiosis tradición-modernidad. Se reconoce su clasicismo revitalizado en la extensión vertical y el acentuado contraste de los palos. Se ejecutó en diversos cuerpos y estilos, en su mayor parte capitales, teniendo en cuenta la importancia de las vías urbanas y las dimensiones del espacio disponible para rotular.

El plano no presenta intervenciones ni actuaciones más allá de algunas anotaciones a grafito. Como anécdota se detectó la corrección de la firma del arquitecto, modificada por el propio Berges para sustituir una firma anterior de la que hace uso en sus primeros proyectos por otra más simplificada con la que firma la mayor parte de sus trabajos posteriores.

\section{Análisis del plano}

Proyectado a escala 1:500, refleja el sector NO y NE de la población antigua enlazando la estación, situada a un kilómetro de la Plaza del Mercado, con el núcleo urbano a través del eje del crecimiento de la nueva ciudad industrial. 
Ocupa un área total de 36 ha y delimita al sur por las calles Rastro y Millán de Priego; al oeste por Puerta del Sol y camino de Pilar Peñamefecit; al norte con el vecinal al Fuerte del Rey; y al este por la carretera de Bailén. En el plano actual de Jaén sus límites estarian definidos por las calles Correa Weglison, Madre Soledad Torres Acosta, Plaza de los Jardinillos, Millán de Priego, Puerta del Sol, Alféreces Provisionales, Avenida de Andalucia, Virgen de la Cabeza y la Avenida de Madrid.

La elección de esta superficie para el ensanche fue la más conveniente, como explica Cueva Matas, por "la tendencia de la población a extenderse a lo largo del Paseo de la Estación; la situación de este Paseo en una vagüada proporcionaría fácil desagüe a sus vertientes; su facilidad de abastecimiento de agua; la necesidad de sanear esta cuenca que recogía una gran parte de las aguas residuales de la población y, vertidas en albercas, se utilizaban para riego de vegetales de consumo; su topografía que, a pesar de ser inclinada y tener acusados taludes y desniveles en algunos sectores, era la más favorable, etc." (CUEVAS MATAS, 1991: 75).

El plano tiene como hilo conductor el Paseo de la Estación, entonces de Alfonso XIII, en cuyas aceras se escenifican grandes bloques de edificación para armonizar con las edificaciones construidas y en construcción y no expropiar lo edificado. Cada una de ellas tendria $200 \mathrm{~m}^{2}$, resultando en todo el paseo 189 viviendas en las que vivirian 945 personas. El resto de las edificaciones en bloque, 672 viviendas, lo sitúa casi en su totalidad en la zona comprendida entre la calle Rastro (Correa Weglison) y la vía de cintura del parque, pudiendo ser habitadas, en las mismas condiciones que las anteriores, por 3360 personas.

Al oeste del Paseo de la Estación (zona comprendida entre Millán de Priego, Puerta del Sol, primer tramo de Muñoz Grandes y el propio paseo), diseña 102 casas familiares modestas, retranqueadas y con jardín privado y público en talud, como solución a lo accidentadísimo del terreno, donde podrían vivir 510 habitantes. Al este del paseo (zona comprendida entre las calles Baeza, Avda. de Madrid, Virgen de la Cabeza y el paseo), las casas baratas, consistentes en 77 familiares y 43 colectivas, en las que vivirian 815 personas. Para separarlas del paseo y dotar a éste de cierta homogeneidad, prevé un grupo de 60 viviendas familiares, desarrolladas en dos plantas sobre otra destinada a comercio o industria, con capacidad para 300 habitantes.

La previsión del ensanche calculaba albergar a 6206 personas, contando también con los penados y los empleados residentes en la prisión, y a la población y religiosas del Asilo de San José (140 y 136 habitantes respectivamente) con lo cual obtiene una densidad de conjunto de 172 habitantes/ha.

El plan de servicios incluía, además del Museo Provincial diseñado por el arquitecto Antonio Florez, un grupo escolar, el mercado y la iglesia, así como áreas verdes y parques como el proyectado bajo la Plaza de las Batallas, Ilamado después Parque de La Vic- toria. Este planteamiento equivale en la superficie de la zona de ensanche dibujada exactamente a $355219.50 \mathrm{~m}^{2}$, de los cuales la superficie edificada es la mitad -177609.75- y la décima parte -35521.95- destinada a parques y jardines.

\section{LA RESTAURACIÓN}

La actuación de conservación-restauración del Plano del Ensanche de Jaén ha tenido que resolver aspectos relativos a las características intrínsecas a este tipo de soporte y a la dificultad de diseñar la propuesta de actuación más conveniente teniendo en cuenta sus dimensiones y condiciones materiales de la pieza.

Cabe destacar que se trata de una tipología abundante en los archivos y bibliotecas de la que, sin embargo, aún no se ha establecido una metodología clara a la hora de abordar su restauración. El principal problema se encuentra en encajar este tipo de obra en una especialidad concreta.

El hecho de poseer un soporte textil ha ocasionado que muchos de los profesionales encargados de la restauración de estas piezas hayan sido especialistas en pintura contemporánea que carecen de conocimientos de la obra documental. Es aqui donde comienzan los problemas. En esta rama de la restauración existe una tendencia generalizada a la utilización de productos artificiales o sintéticos fuertes, generalmente a base de disolventes no acuosos o termofusibles, para el tratamiento de los soportes. El uso de estos productos poco apropiados para materiales como el tejido o el papel se debe al miedo que produce la aplicación de sustancias al agua para el tratamiento de obras cuyos elementos gráficos son solubles, lo que explica un desconocimiento generalizado de cómo se comportan y deben ser tratados.

Si bien el tejido es el soporte pictórico tradicional más frecuente, hay que destacar que para la pintura es sometido a una serie de tratamientos más o menos complejos, que consisten en aplicar una serie sucesiva de capas o preparaciones que alteran significativamente (tanto en aspecto como en propiedades físicas) las características del tejido base. La finalidad de este proceso es convertir la tela en un soporte semi-rígido que sea capaz de recibir una serie de técnicas basadas en la aplicación de pigmentos y aglutinantes muy pesados o con una masa significativa.

En el caso del plano que nos ocupa, el tejido que hace de soporte es tratado de forma radicalmente distinta porque recibe unos tratamientos industriales ideados originalmente para productos papeleros, ya que el objetivo fundamental es que la tela se parezca y se comporte lo más parecido posible al papel. La tela es, de hecho, tratada como si fuera un papel porque su propia composición química lo permite. Hay que tener en cuenta que las fibras papeleras son las mismas que las utilizadas para los tejidos de fibra vegetal, de los cuales el algodón, el lino y el cáñamo son las más habituales en España. 


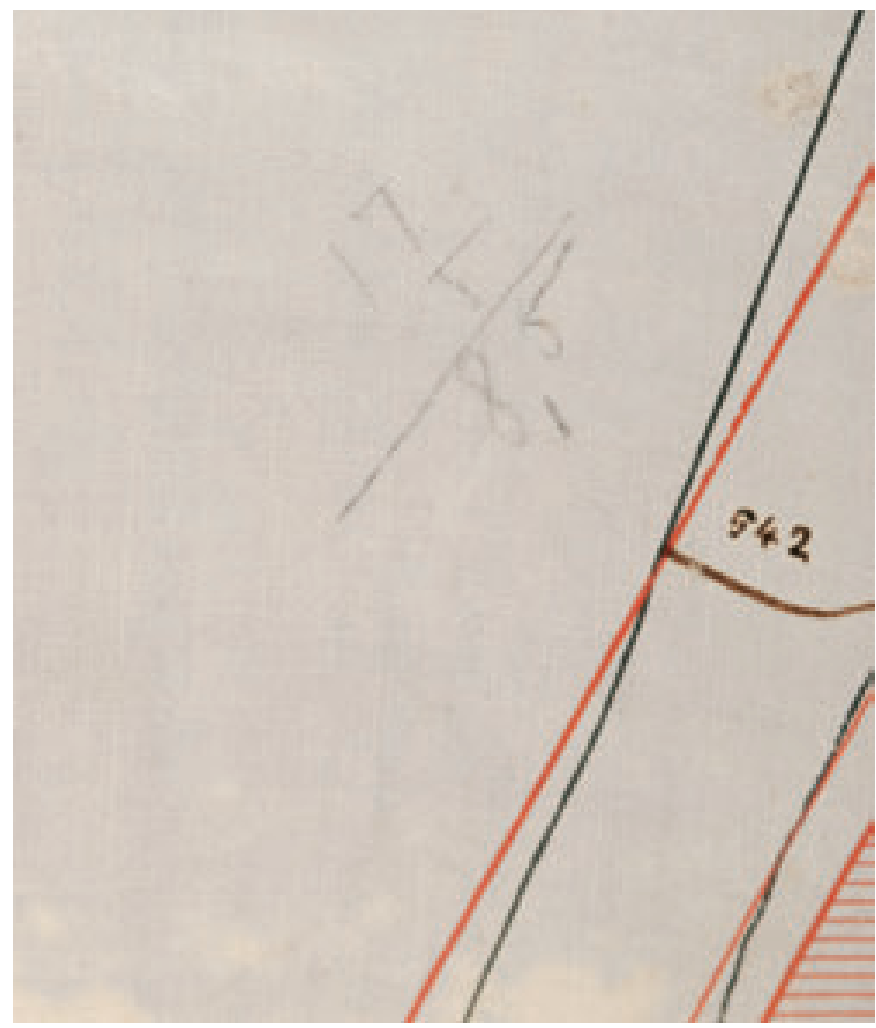

8. Marcas originales a lápiz de grafito. Detalle del anverso, zona superior central. Foto: Eugenio Fernández Ruiz, IAPH

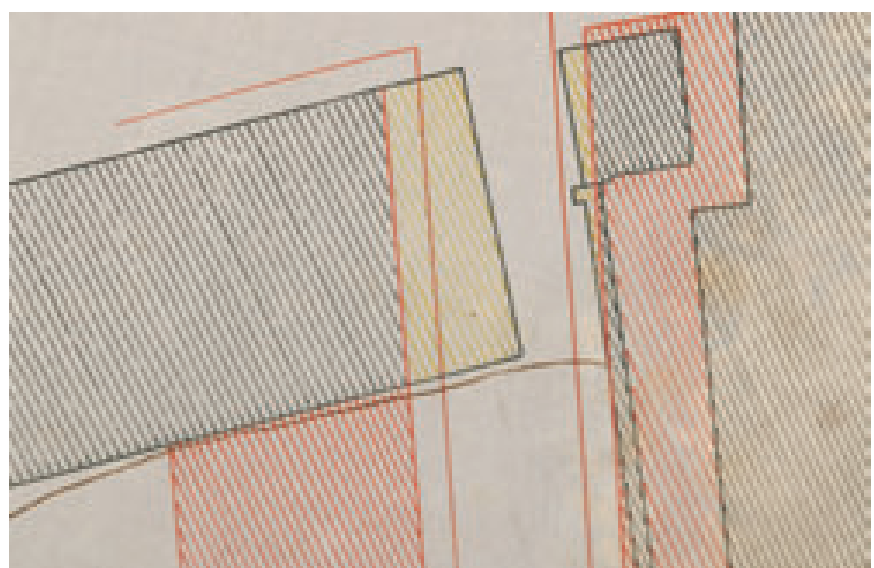

9. Tintas al agua en tonos negro, rojo, amarillo y pardo. Detalle del anverso, zona superior central. Foto: Eugenio Fernández Ruiz, IAPH

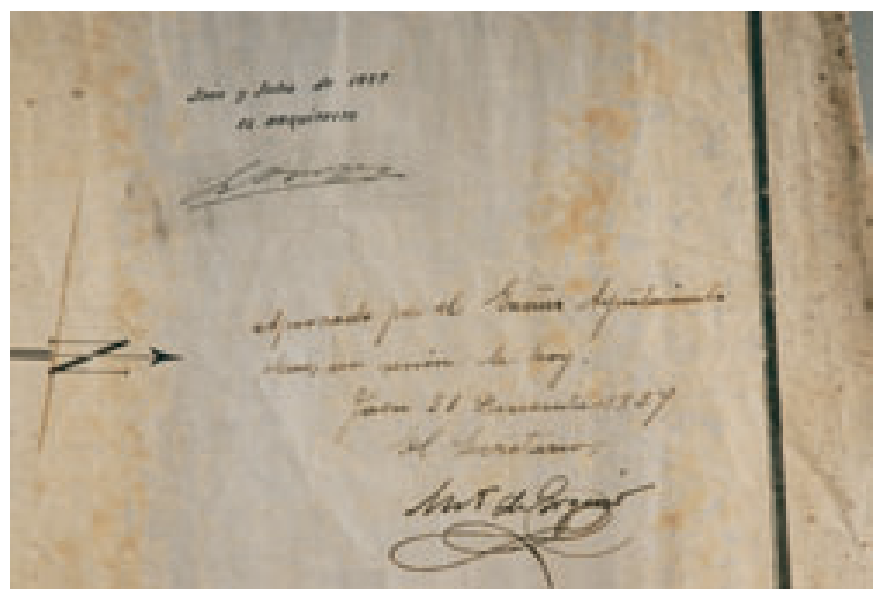

10. La fecha y firma de Luis Berges fue manuscrita con tinta negra al agua, mientras que las del secretario se realizaron con tintas de naturaleza metaloácida. Foto: Eugenio Fernández Ruiz, IAPH
Otra diferencia fundamental con la obra pictórica es que la totalidad de las técnicas empleadas en estos planos son propias de la obra gráfica o documental. De hecho, son las mismas tintas caligráficas y de dibujo al agua que las empleadas sobre papel. En el Plano de Jaén encontramos específicamente tres tipos de elementos gráficos bien diferenciados: el lápiz de grafito, las tintas de colores al agua y las tintas metaloácidas.

Por los motivos anteriormente mencionados, podemos decir que la tela almidonada empleada para la ejecución de planos técnicos (Arquitectura, Urbanismo, Ingenieria, etc.), desde finales del siglo XIX hasta mediados del XX, es un soporte documental, de carácter gráfico según su contenido y con una técnica de ejecución manuscrita y manual. Por tanto, deben ser tratados como documentos a la hora de abordar su restauración y conservación, ya que son los profesionales especialistas en patrimonio documental y gráfico los auténticos conocedores de los problemas que afectan tanto al soporte como a los elementos gráficos de la obra, del comportamiento de las tintas ante cualquier técnica aplicada a la restauración de documentos y de la metodología y los procesos adecuados para este tipo de obra.

\section{Diagnosis y estado de conservación}

El plano llega a las instalaciones del IAPH enrollado sobre sí mismo, estado en el que debió encontrarse durante largo tiempo. Esta disposición del plano junto con el plegado han sido las únicas formas factibles de almacenarlo hasta el momento.

En primer lugar y antes de su desplegado, se le realiza una toma de muestras de material biológico y es sometido a un tratamiento de desinfección-desinsectación mediante atmósfera controlada con gases inertes para la desactivación de la actividad biológica presente. Este sistema, de eficacia comprobada, resulta inocuo porque carece de productos químicos activos que puedan reaccionar de forma adversa con los materiales de los que se componen las obras, sobre todo aquellos que contienen materiales orgánicos. Dicho tratamiento se realiza de ordinario en el IAPH como método curativo que, en este caso, está perfectamente justificado, ya que la obra presentaba indicios evidentes de contaminación microbiológica que serán descritos más adelante.

Una vez extraído de la atmósfera controlada, es trasladado al Taller de Patrimonio Documental y Bibliográfico y se procede a un estudio exhaustivo de los materiales compositivos, de las técnicas de producción y de las alteraciones presentes en el plano para elaborar, al fin, un diagnóstico del estado de conservación de la obra.

Los estudios previos a la intervención ponen de manifiesto que la obra es un plano técnico, compuesto de un soporte de factura industrial de tela de algodón almidonada, prensada y satinada. Su aspecto original sería el de un tejido de color blanco grisáceo y parcialmente transparente (aunque el envejecimiento de 


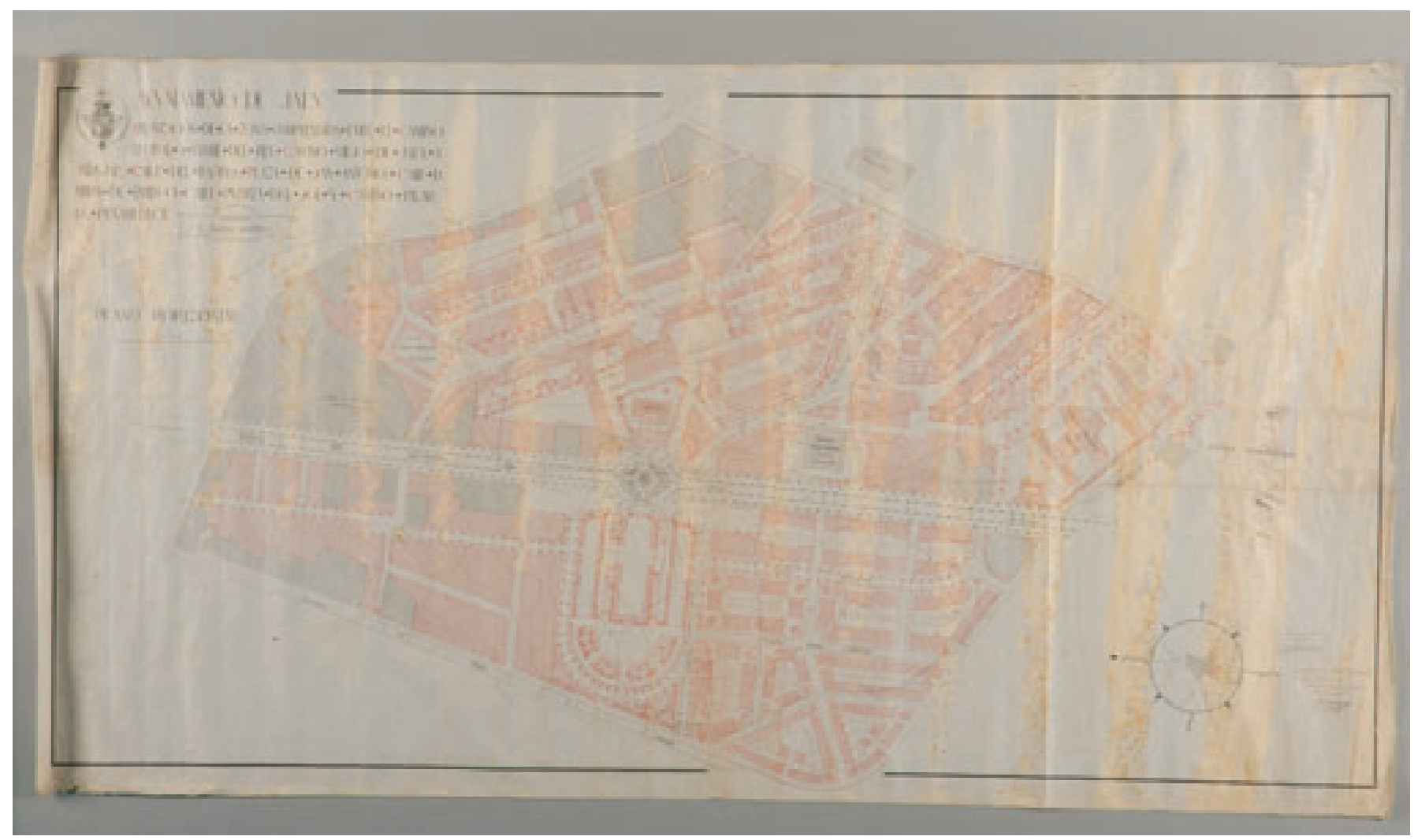

11. Estado del plano antes de su restauración. Foto: Eugenio Fernández Ruiz, IAPH

sus fibras hace que estas características organolépticas hayan variado), con un cierto brillo más acentuado en el anverso que en el reverso y una consistencia relativamente rígida. Este soporte contiene unos elementos sustentados aplicados de forma manual (y manuscrita) que se dividen en tres grupos fundamentales: lápiz de grafito para el dibujo preparatorio y algunos cálculos accesorios (imagen 8); tintas al agua en tonos negro, rojo, amarillo y pardo para el dibujo del plano (imagen 9), y en la fecha y firma de Luis Berges en negro; tintas caligráficas de naturaleza metaloácida para la fecha y firma del secretario del ayuntamiento (imagen 10).

Los resultados del diagnóstico indican que la mayor parte del deterioro que presentaba el plano es consecuencia más o menos directa de las dificultades de manipulación y de almacenaje propias de las obras de gran formato, mientras que el resto de alteraciones forman parte del envejecimiento natural de los materiales que la componen.

Los daños más significativos del Plano del Ensanche de Jaén son debidos a los sucesivos plegados y enrollados, a los que fue sometido a lo largo del tiempo, y a su ubicación desconocida en un lugar inadecuado en el que las condiciones ambientales (suciedad, exceso de humedad, alta temperatura y mala ventilación) formaron un caldo de cultivo idóneo para la proliferación de insectos y microorganismos (imagen 11).

Estas alteraciones se manifiestan en forma de abundante polvo, detritos de insectos y suciedad general repartida por todo el soporte.
El tejido del soporte tiene alteraciones cromáticas que consisten en la adquisición de un tono gris azulado y una pérdida de transparencia no originales y que son fruto de la oxidación de sus fibras. Desgraciadamente esta es la alteración más común en este tipo de obras porque forma parte de su envejecimiento natural.

También aparece una significativa pérdida de color por blanqueo que se manifiesta en forma de grandes manchas blanquecinas o amarillentas formando franjas verticales más o menos paralelas, lo que indica que el plano ya se encontraba enrollado cuando sufrió esta alteración. La forma y disposición de estas manchas blancas demuestran que el plano fue enrollado de izquierda a derecha dejando la cara del dibujo hacia adentro, posiblemente para protegerla (imagen 14). Este efecto de blanqueo es consecuencia de la presencia prolongada de humedad en el lugar de ubicación del plano, cuyo soporte, al ser muy higroscópico, absorbió el agua.

\section{Algunos de los procedimientos y materiales utilizados para la restauración del Plano son experimentales y merece la pena llevar un seguimiento de su evolución}




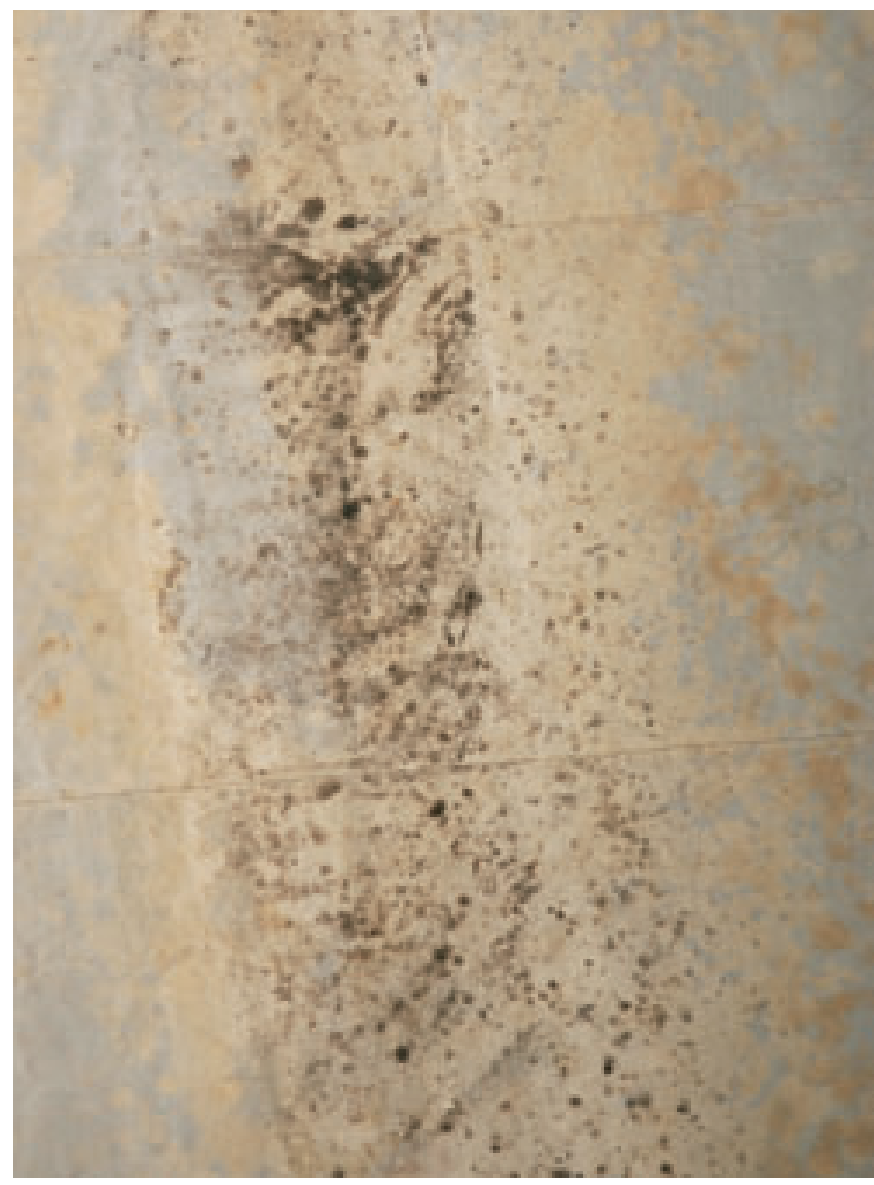

12. Debilidad y pérdida de consistencia física en zonas afectadas por humedad y microorganismos. Detalle del anverso, zona central izquierda. Foło: Eugenio Fernández Ruiz, IAPH

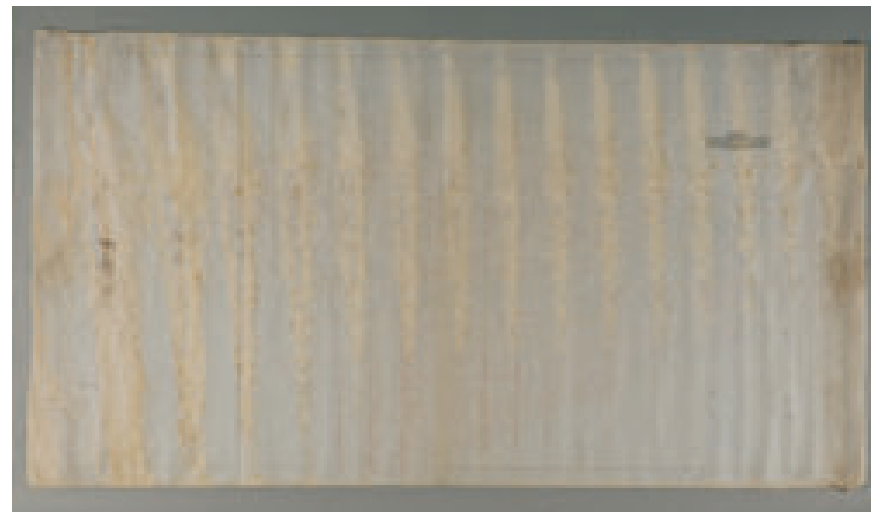

14. Pérdida de color del soporte por acción de la humedad. Foto: Eugenio Fernández Ruiz, IAPH

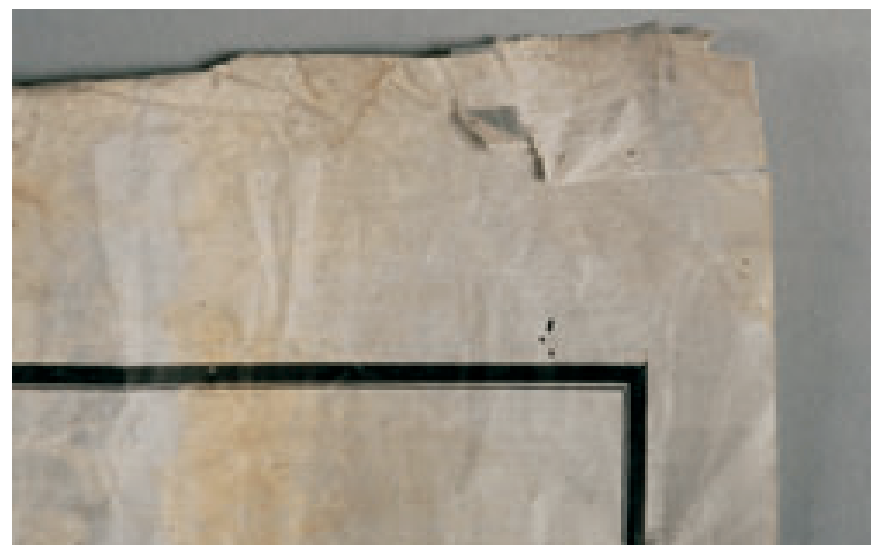

16. Rotura del soporte con reparaciones con cinta "cello". Detalle del anverso, ángulo superior izquierdo. Foto: Eugenio Fernández Ruiz, IAPH
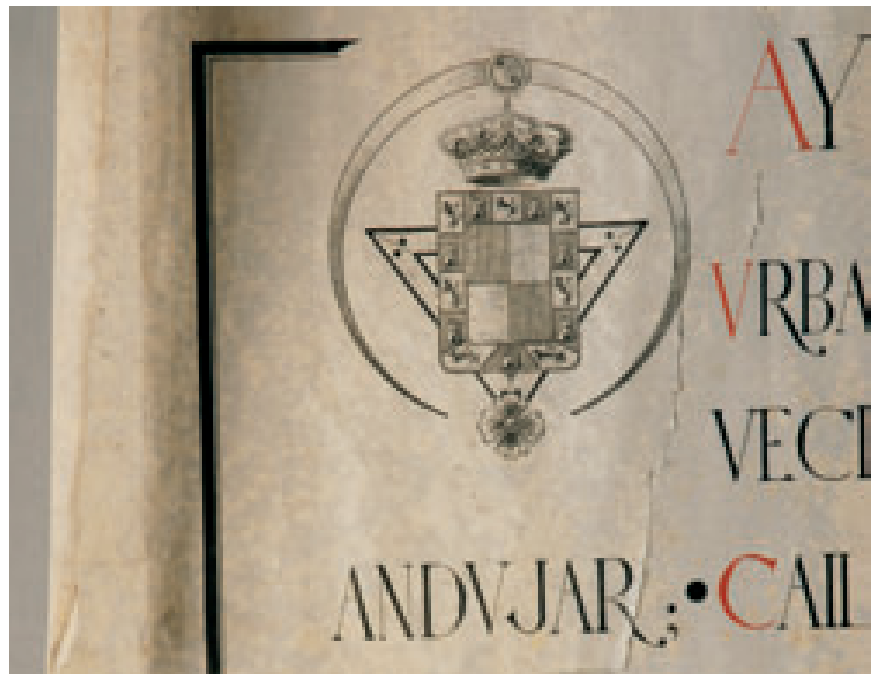

$\backslash \mathrm{IIIIII \cdot DE} \cdot \mathrm{PR} \|$ $\mathrm{DE} \cdot \mathrm{PE} \overline{\mathrm{N}} \mathrm{N}$ IEFE

13. Gran desgarro en ángulo superior izquierdo. Foto: Eugenio Fernández Ruiz, IAPH

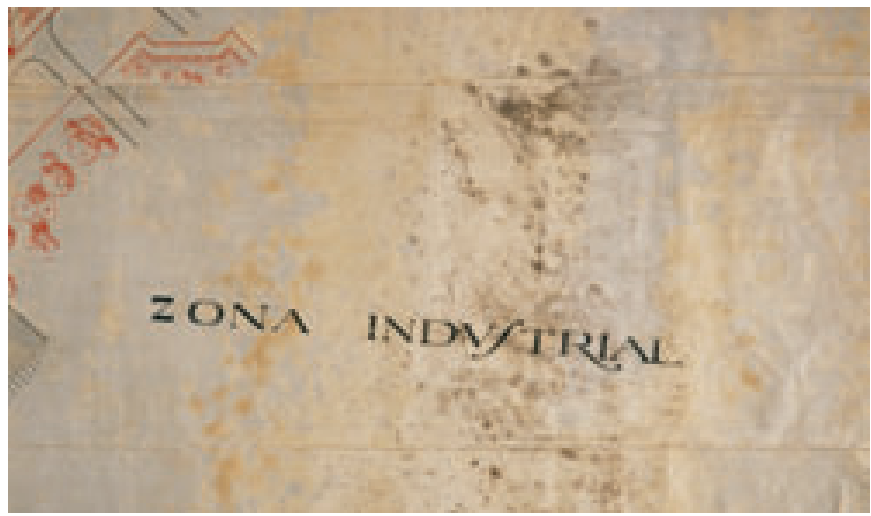

15. Deformaciones del soporte en forma de pliegues y arrugas. Detalle del anverso, zona central derecha. Foło: Eugenio Fernández Ruiz, IAPH

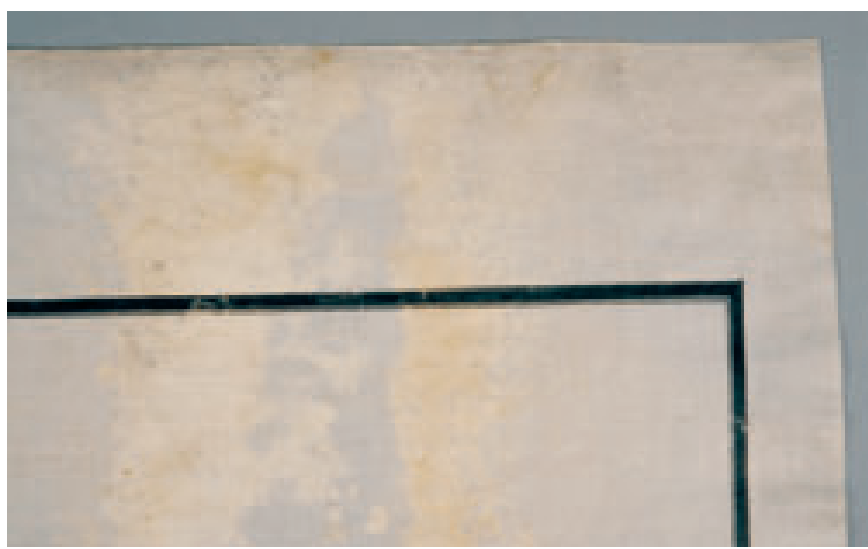

17. Estado final de ángulo superior derecho tras la restauración. Foło: Eugenio Fernández Ruiz, IAPH 
En este periplo se produjo la pérdida de su almidonado original y la formación de unas colonias de microorganismos compuesta por la combinación de varias especies de hongos y de bacterias. Este ataque de microorganismos es más acentuado en el margen derecho, donde las marcas de humedad son más fuertes, ya que era la zona más externa del enrollado y la más afectada por la humedad y se manifiesta en forma de un moteado de color oscuro (imagen 12).

La acción de estos agentes biológicos provoca, además, la formación de manchas por tinción y la acidificación de las fibras del soporte. Aunque no ha sido posible la medición de los niveles de acidez de la zonas del soporte afectado por microorganismos (lo que hubiera supuesto la aparición de manchas o cercos por la humedad que hay que aplicar para el uso del pHimetro), cabe destacar que las zonas no afectadas tienen un pH de 5.2, lo que indica que la fibra textil ya se ha degradado produciendo ácidos. Como consecuencia de ello el tejido presenta una debilidad en las zonas blanqueadas que le dan un aspecto suave, mate, algodonoso y una acentuada pérdida de consistencia física. La combinación de estos agentes de deterioro provocan, además, la pérdida de parte de la humedad compositiva de la fibra textil, que presenta también un aspecto reseco.

Destacan especialmente las deformaciones presentes en el tejido ya que existen numerosas marcas horizontales y verticales que son producto de plegados anteriores y abundan deformaciones verticales en forma de pliegues, arrugas y alabeos que son consecuencia del enrollado posterior. Las áreas blanquecinas presentan otras deformaciones causadas por pérdida de su almidonado y de parte de su consistencia física, lo que ha ocasionado diferencia de tensiones con las zonas no afectadas del tejido (imagen 15).

Las deformaciones coinciden con numerosas grietas y desgarros producidos por los sucesivos plegados. Los márgenes del soporte, al ser las zonas más expuestas a agresiones físicas, aparecen también muy debilitados por pliegues y arrugas y presentan numerosas roturas, algunas con desprendimiento y pérdida de soporte sobre todo en los ángulos. Destaca especialmente un gran desgarro situado en el ángulo superior izquierdo del soporte, donde está rotulado el título del plano (imagen 13).

Algunas roturas del soporte han sufrido intentos de reparación por medio de cinta autoadhesiva plástica blanca (cello) como los desgarros del ángulo superior derecho e izquierdo del reverso del plano. Por su estado puede deducirse que fueron colocadas recientemente, por lo que aún no habia envejecido la tira plástica ni su adhesivo. Estos intentos de reparación aparecen con frecuencia en el material de archivo y suponen, en la mayor parte de los casos, una causa importante de alteración por lo poco adecuado de sus materiales y el pésimo envejecimiento que comportan (imágenes 16 y 17). Hay presencia también de lagunas producidas por quemaduras de cigarro como la que aparece en la zona inferior del plano.

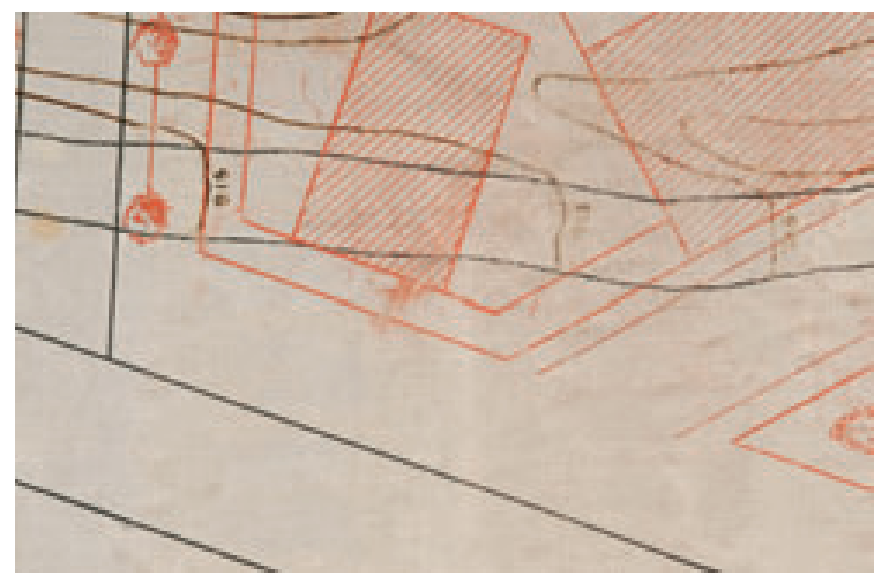

18. Desplazamiento y pérdida de tintas por humedad y roces. Detalle del anverso, margen inferior central. Foto: Eugenio Fernández Ruiz, IAPH

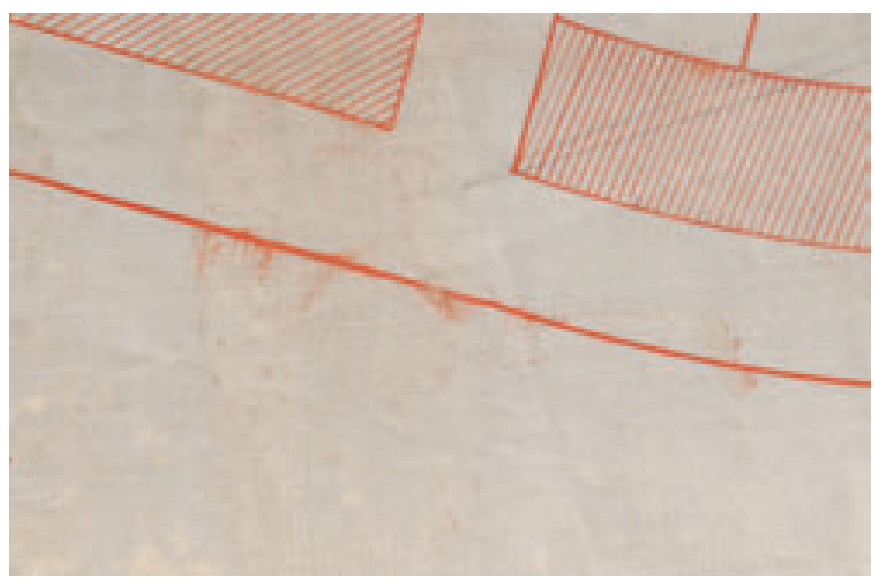

19. Desplazamiento de tintas por humedad. Detalle del anverso, margen inferior central. Foto: Eugenio Fernández Ruiz, IAPH

En lo relativo a los elementos gráficos habria que destacar su buen estado de conservación. Apenas encontramos pequeñas solubilizaciones con desplazamiento de las tintas por causa de la humedad, pero de muy poca importancia, y ligeras pérdidas de algunos elementos gráficos por sobreesfuerzo del soporte en las marcas de plegado. Por lo demás, existe una ligera acción corrosiva de las tintas metaloácidas que forman parte de su propio envejecimiento natural (imagen 18).

La principal causa de degradación de las tintas caligráficas es la luz, sobre todo la solar, lo que indica que el óptimo estado en el que se hallan los elementos gráficos es consecuencia precisamente de la poca incidencia que este agente medioambiental ha tenido sobre el plano (imagen 19).

\section{Tratamiento y actuaciones realizadas}

El diagnóstico y las características de la obra objeto de nuestro trabajo son las que determinan los parámetros de una propuesta de tratamiento que se basa, además, en la metodología de trabajo desarrollada en el IAPH. Se decide, por tanto, que es necesario diseñar una intervención de restauración del plano cuyos objetivos fundamentales sean detener y corregir los efectos de su deterioro para prolongar su vida física y la recuperación de sus 


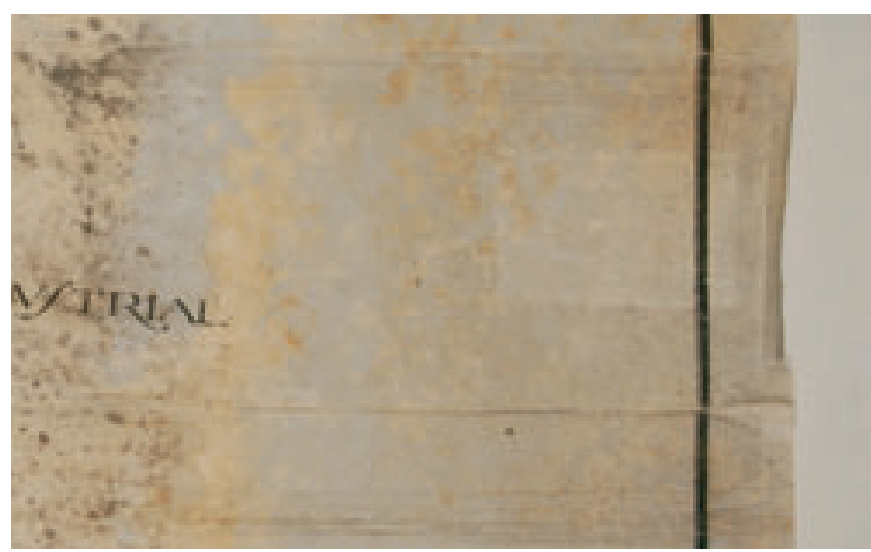

20. Cata de limpieza mecánica de la suciedad sólida superficial. Detalle del anverso, margen derecho. Foto: Eugenio Fernández Ruiz, IAPH

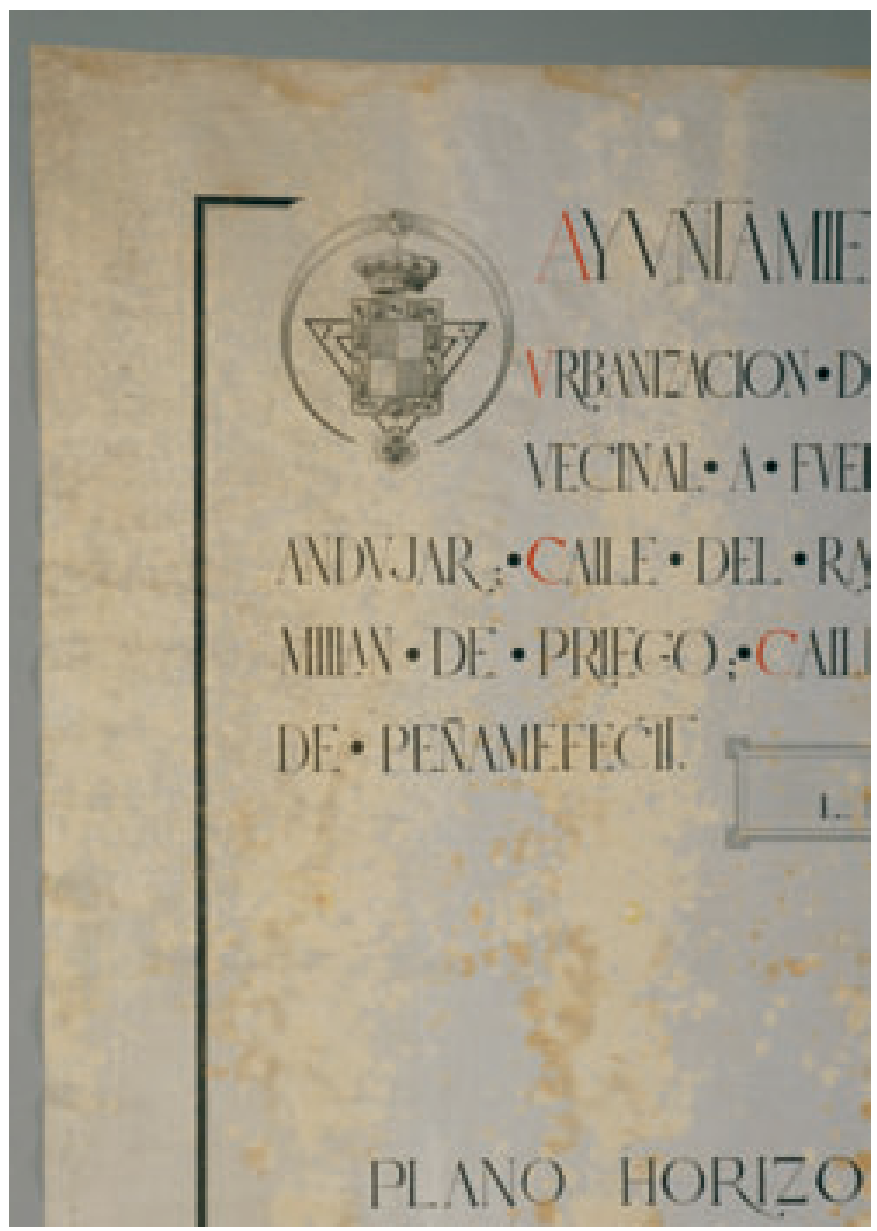

22. Unión y refuerzo de desgarro del ángulo superior izquierdo del plano. Foto: Eugenio Fernández Ruiz, IAPH

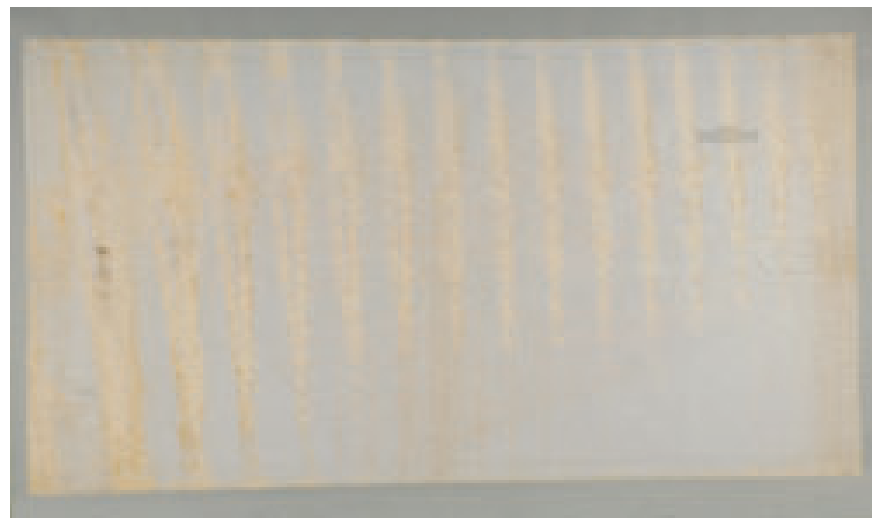

25. Estado final del reverso del plano tras su restauración.

Foło: Eugenio Fernández Ruiz, IAPH

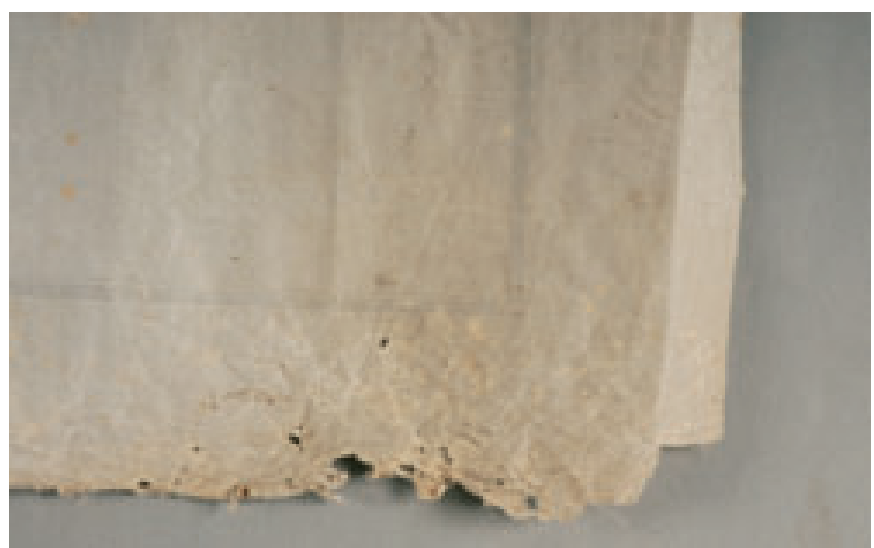

21. Deterioros con pérdida de soporte en ángulo inferior derecho del plano. Foto: Eugenio Fernández Ruiz, IAPH

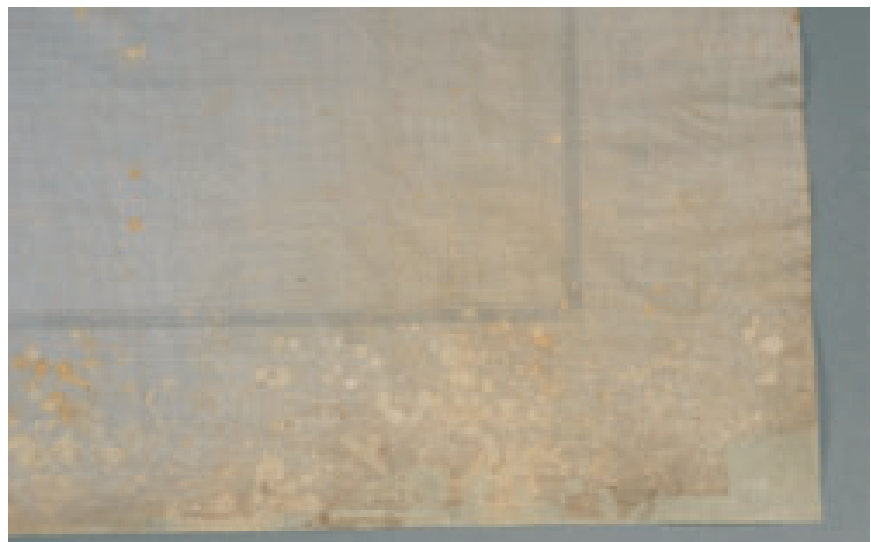

23. Alisado, refuerzo y reintegración de las lagunas del soporte. Detalle del anverso, ángulo inferior derecho. Foto: Eugenio Fernández Ruiz, IAPH

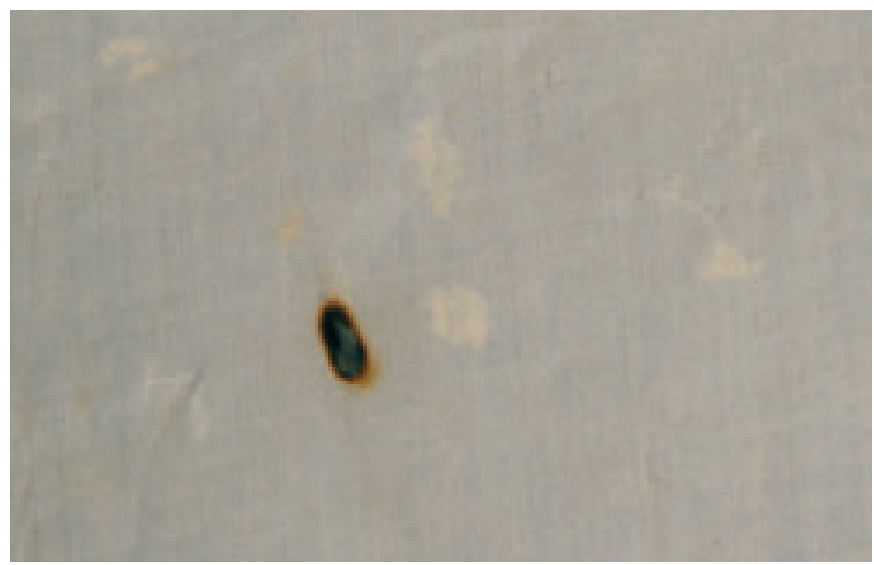

24. Quemadura de cigarro en el soporte. Detalle del anverso, zona inferior izquierda. Foto: Eugenio Fernández Ruiz, IAPH

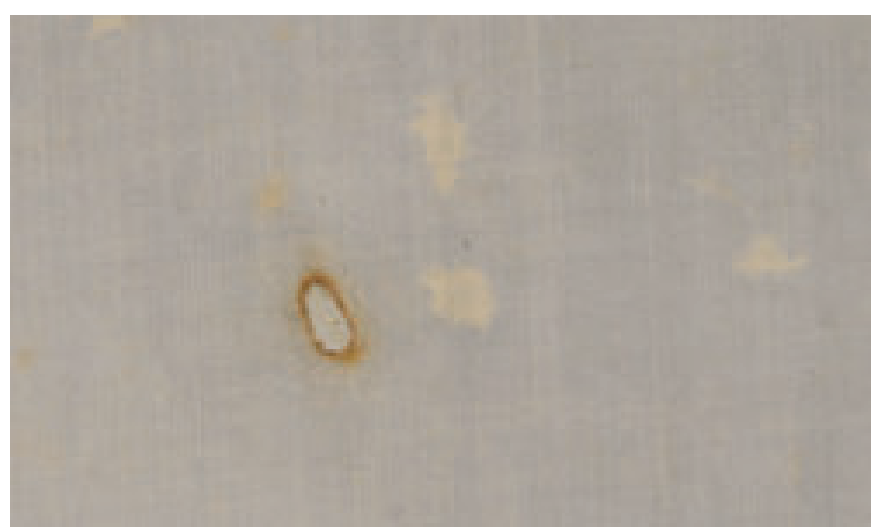

26. Resanado e injerto de laguna del soporte producida por quemadura de cigarro. Foto: Eugenio Fernández Ruiz, IAPH 
características estéticas, materiales y funcionales. Para la óptima ejecución de esta intervención es necesario que sea llevada a cabo por un equipo interdisciplinar de profesionales formado por conservadores-restauradores de documento gráfico y tejido, historiador, arquitecto, fotógrafo y científicos en Física, Quimica y Biología.

El tratamiento aplicado al Plano del Ensanche de Jaén consiste en una serie de procesos cuya ejecución resultó lenta y costosa debido a la dificultad que entrañaba sus enormes dimensiones. No es difícil imaginar lo complejo que resultó alcanzar las zonas centrales del plano, lo que obligó a enrollarlo cuidadosamente sobre un tubo grueso en algunas fases del trabajo.

Estos procesos se inician con una limpieza mecánica, en seco, de la suciedad sólida superficial mediante acción mecánica con instrumental variado, esponjas de látex y resinas de diferentes durezas. La limpieza se realizó por ambas caras del soporte y fue lo más exhaustiva posible para favorecer así la óptima visualización de los elementos gráficos. Especial cuidado requería la limpieza alrededor de los trazos a lápiz de grafito del dibujo preparatorio, para que no se perdiera ningún trazo. Las tareas de limpieza se completaron con la eliminación mecánica de las tintas desplazadas por humedad para la recuperación de la definición del dibujo, ya que su localización en zonas no originales podía confundir al espectador (imagen 20).

La eliminación de elementos añadidos (cinta autoadhesiva) de intervenciones anteriores se llevó a cabo levantando mecánicamente la cinta plástica de manera que no se desfibrara el tejido en los bordes de las roturas; los restos de adhesivo se terminaron de retirar con la aplicación puntual de pequeñas cantidades de acetona.

Tras la eliminación de la suciedad y elementos añadidos ya pueden abordarse los tratamientos en húmedo. El hecho de contener elementos gráficos solubles no significa que se tenga que erradicar completamente los tratamientos con productos acuosos habituales en el tratamiento de las obras documentales con soporte de fibras vegetales. Es necesaria la presencia de humedad para recuperar la lisura original del soporte porque sólo asi recuperan su forma las fibras celulósicas. Para ello se preparó un consolidante a base de un ligero adhesivo de almidón de trigo en agua que se mezcló con hidroxipropilcelulosa muy diluida en etanol en una proporción del 10\%. La combinación de estos dos adhesivos se debe a la afinidad evidente que ambos mantienen con los materiales originales. El engrudo de almidón es, probablemente, el encolante utilizado en el apresto original del soporte y su uso como consolidante favorecerá que las zonas tratadas vuelvan a comportarse de forma similar a las que no se han deteriorado. El otro adhesivo es un derivado de la celulosa y su composición servirá para recomponer la estructura química de la fibra textil deteriorada. El ligero aporte de etanol en la mezcla final es suficiente para evitar solubilizaciones de cual- quiera de las tintas y su proporción fue establecida tras superar positivamente las pertinentes pruebas de solubilidad y/o viraje de los elementos gráficos. Otro motivo importante para el uso de estos dos adhesivos es su reversibilidad y que no alteran las cualidades estéticas del soporte original.

Las áreas afectadas por la humedad, con pérdida del almidonado original y ataque de microorganismos, fueron consolidadas mediante sucesivas aplicaciones de la mezcla consolidante en pequeñas áreas de unos $10 \mathrm{~cm}^{2}$, ya que así el proceso de secado es más rápido y fácil de controlar. A la impregnación con pincel le seguía un secado rápido con espátula termostática entre láminas de remay, seguida de un remate final sin remay y con presión (sin frotar) que simulara en aspecto los procesos finales de prensado y satinado del soporte original. Este proceso se llevó a cabo por el anverso del plano para controlar en todo momento el óptimo estado de las tintas.

Este mismo sistema fue utilizado para el alisado y la consolidación de las marcas de plegado, ya que la humedad aportada por el consolidante era suficiente para eliminar la deformación de las fibras textiles y la mezcla de adhesivos dieron rigidez y fuerza a las zonas más debilitadas por acción mecánica, haciendo que los pliegues no volvieran a marcarse.

Momento especialmente delicado fue decidir el tratamiento que se debía aplicar para solucionar las roturas y las pérdidas de soporte. Con vistas al refuerzo y la unión de grietas y desgarros se decidió aplicar un sistema similar a la laminación de documentos que consiste en la adhesión por el reverso de un papel japonés, generalmente un tissue, que le dé resistencia al soporte original. Sólo que, en este caso y debido a que el soporte original es un tejido, en vez de papel se empleó una crepelina de seda natural. La crepelina de seda es un tejido de una resistencia física extraordinaria, pero con una gran finura, y presenta una trama y urdimbre muy abierta que hace que sea muy estable a cambios dimensionales, con lo que podemos asegurar que se adaptará fácilmente a las dilataciones o contracciones propias del tejido del soporte del plano ante los cambios de las condiciones medioambientales.

El problema de la adhesión de la crepelina fue uno de los puntos más conflictivos. Era necesario emplear un material que no aportara humedad, ya que no sería posible abordar el secado de los refuerzos sin provocar deformaciones al soporte. Por otro lado, una humectación general o el uso de otros disolventes podian llegar a alterar significativamente el aspecto suave, brillante y satinado original de la superficie del tejido. Así que se optó por una adhesión en seco mediante calor de un adhesivo acrilico en lámina ${ }^{8}$ usado habitualmente para la restauración de documentos. El empleo de un adhesivo en lámina asegura una adhesión homogénea con la utilización de una cantidad mínima de material, lo cual dará a los refuerzos del plano un comportamiento estable y homogéneo. 
Los refuerzos para grietas y desgarros se prepararon manualmente mediante la adhesión del acrílico en lámina con espátula termostática ya que el empleo de máquina laminadora podia hacer que el adhesivo traspasara completamente la crepelina de seda, produciendo brillos indeseados y problemas posteriores de adhesión debidos al exceso de calor y presión. Luego se fueron recortando los trozos necesarios para los refuerzos con tijeras, desfibrando ligeramente sus bordes, y aplicándolos por el reverso del plano con la espátula termostática. En este caso, se pudo observar que la adhesión de la crepelina directamente con la espátula, sin el uso de remay, evita la aparición de brillos antiestéticos y daba a la crepelina una transparencia extraordinaria que la hace prácticamente invisible (se aprecia incluso mejor al tacto que a la vista). Cuando se trataba de desgarros, además de los refuerzos por el reverso del soporte, fue necesario adherir finas tiras de crepelina en el anverso sobre los bordes, aunque nunca cubriendo elementos gráficos, para terminar de fijar los deshilachados y evitar que se levanten con el tiempo (imagen 22).

Para la realización de los injertos de las lagunas del soporte se ideó un sistema que es una combinación de los injertos de papel y del sistema de refuerzos con crepelina de seda anteriormente explica- do. Se hicieron injertos con papel japonés teñido en tono similar al tejido del plano y recortados siguiendo la forma de la laguna mediante desfibrado para evitar el corte limpio. Una vez recortado, el injerto se cubre por ambas caras con trozos de crepelina de seda a los que se les deja una solapa, que son las que se adhieren al soporte. De esta forma, el injerto de papel no monta sobre el tejido original en ningún momento quedando totalmente a ras del original. Además, la crepelina de seda le da al conjunto del injerto un aspecto y un tacto similar a los del tejido, integrando estéticamente los injertos (imágenes 21, 23, 24 y 26).

Tras la aplicación de estos tratamientos que tan buen resultado dieron tanto en lo estético como en lo funcional, sería interesante someter esta obra a un control periódico (cada 2 años) que tenga como objetivo comprobar la efectividad de los procedimientos y de los materiales empleados en ellos. Si bien los tratamientos aplicados son habituales en los trabajos de restauración de documentos, algunos de los procedimientos y de los materiales utilizados para la restauración del Plano del Ensanche de Jaén, aunque cumplen con los criterios básicos de conservación, son experimentales y merece la pena llevar a cabo un seguimiento de su evolución (imagen 25).

\section{PROPUESTA DE SISTEMA EXPOSITIVO}

- Debido a los problemas de espacio para su almacenaje, y para favorecer su completa visualización, seria conveniente un montaje mediante enmarcado en formato vertical.

- La estructura del enmarcado se realizará en aluminio, para evitar el peso excesivo de todo el montaje, ya que éste será de grandes dimensiones.

- Hay que incluir orificios de ventilación en los laterales de la estructura del marco. Habría que evitar los márgenes inferior y trasero del enmarcado porque las paredes y el suelo pueden transmitir humedad, y la zona superior, porque sería vía de entrada de polvo y suciedad general.

- Los orificios de ventilación deben taparse con tejido de trama abierta que permita la entrada de aire pero no la de insectos que puedan afectar al plano.

- El tablero-base sobre el que descansará el plano debe ser de material de conservación documental y de peso lo más ligero posible. Por cuestiones estéticas, las dimensiones idóneas podrían ser $1700 \times 2900 \mathrm{~mm}$ aprox.

- Debido a las grandes dimensiones del original, sería conveniente que el tablero-base cuente con una ligera inclinación para que el plano descanse sobre él y no tenga que ser adherido.

- El sistema de sujeción más adecuado del plano a su montaje sería mediante suspensión. Conviene evitar la inmovilización del plano mediante la adhesión directa al tablero-base porque esto podria dar lugar a deformaciones o tensiones causadas por los movimientos (dilataciones y contracciones) con los que el tejido reacciona ante los cambios de las condiciones medioambientales. El sistema ideado consiste en la adhesión con adhesivo de doble cara de cintas verticales de $1,5 \mathrm{~cm}$ de ancho y de fibra sintética en el margen superior del reverso del plano. Estas cintas se distribuirán a una distancia de $20 \mathrm{~cm}$ cada una y estarán sujetas a la estructura superior del marco de manera que el plano quede suspendido, pero descansando sobre el tablero-base. La colocación de las cintas permitirá el movimiento natural de la tela del plano sin forzarla y sin producir deformaciones antiestéticas en forma de ondulaciones, alabeo o marcas de tensión.

- Al no ir sujeto por la zona inferior, sería conveniente la colocación de pesos por el reverso del margen inferior del plano. Estos pesos podrían ser pequeños trozos de cartón neutro adheridos con adhesivo de doble cara.
- El sistema de cierre delantero del montaje debe ser de metacrilato, no vidrio, y contener el máximo filtro de radiación ultravioleta. El uso de resinas sintéticas y no vidrio evitará problemas graves en caso de rotura accidental y restará peso al montaje definitivo ya que el vidrio es más pesado.

- La distancia entre la obra y el metacrilato delantero debe ser de al menos $4 \mathrm{~cm}$ para dejar una cámara de aislamiento de la humedad relativa del aire que puede condensarse sobre la superficie del metacrilato cuando se producen fluctuaciones de la temperatura y la humedad relativa del aire.

- Todos los materiales anteriormente mencionados deben ser de conservación, es decir, inertes (no sujeto a reacciones químicas), libres de ácidos, bases fuertes (como los productos clorados con los que se blanquean papeles y cartones) u otras sustancias químicas nocivas para el tejido y las tintas; y carecer completamente de elementos metálicos que puedan clavarse, arañar o manchar la obra con oxidaciones indeseadas. Cualquier adhesivo empleado debe ser de eficacia probada en conservación y carecer de un envejecimiento que aporte problemas al original. 


\section{CONCLUSIONES}

Habria que terminar resaltando que es innecesaria la restauración de esta obra si luego no se eliminan o atenúan las circunstancias causantes de su deterioro. Como las causas de alteraciones más importantes localizadas en este plano son aportadas por su propio uso, la sensibilidad de sus materiales y los problemas de manipulación y almacenaje por su gran formato, es importante dotarlo de un sistema de conservación permanente que evite futuras agresiones mediante la inclusión de elementos de protección efectivos que puedan asegurar su futura permanencia.

Como el paso del tiempo produce necesariamente un cambio en las funciones del plano -entre ellas, que la función estética o la investigación de sus circunstancias históricas y su contenido documental toman cada vez más protagonismo-, sería importante incluirlo en un sistema expositivo que, además, evitará tener que extraerlo cada vez que sea necesaria la visualización, investigación y/o exposición del plano. Si bien un sistema expositivo permanente no es la forma más adecuada de proteger un documento, cabe señalar que, en este caso, es la única opción factible al no existir muebles con la envergadura suficiente para contener obra de se- mejantes dimensiones, lo que obligaría a volver a plegar o enrollar el plano. En este caso, la ejecución del sistema expositivo de conservación debe ser completada con un estricto control de las condiciones medioambientales, mediante la ubicación de la obra en un lugar seguro, estable y con una reducción de la iluminación tanto solar como artificial. También es muy importante para la conservación preventiva la realización de una copia digital que evite el uso directo del plano.

La puesta en valor de los planos técnicos existentes en los Archivos y Bibliotecas públicos o privados es una labor fundamental a la hora de preservar esta parte tan amplia e importante de nuestro patrimonio documental. Los planos no tienen únicamente un valor funcional y estético, son además testigos fundamentales de la evolución conceptual, estética y técnica de las obras de Arquitectura, Urbanismo e Ingeniería, y de la forma en que esta evolución ha sido recogida a lo largo de la historia, dando lugar a fuentes históricas y documentales de gran valor. Por ello es necesario hacer hincapié en la conservación del aspecto material de estos archivos y bibliotecas. Animamos a las instituciones públicas, arquitectos y demás profesionales dedicados a este campo y a la sociedad en general, a realizar un mayor esfuerzo para preservar y difundir este legado.

\section{Notas}

${ }^{1}$ http://www.mheu.org/fr/chronologie/grands-travaux-paris.aspx

2 http://en.wikipedia.org/wiki/Jules Guerin

\section{FICHA TÉCNICA}

${ }^{3}$ www.library.cornell.edu/Reps/DOCS/nyc1811plan.jpg

${ }^{4}$ Véase BERGES ROLDÁN y otros, pp. 81-83; $131 ; 255-263$

${ }^{5}$ Fibra compuesta de un 90-95\% de celulosa.

${ }^{6}$ Calificación técnica que define el ligamento más simple utilizado en la fabricación de tejidos.

${ }^{7}$ Cianotipo o papel al ferroprusiato es una copia fotosensible obtenida en pape sensibilizado con ferroprusiato o ferrocianuro de potasio, de color azul intenso, que se usó en la reproducción de planos y dibujos y en trabajos de imprenta.

${ }^{8}$ Archibond ${ }^{\circledR} \sin$ soporte.

\section{Bibliografía}

BERGES ROLDÁN, L.; GALERA ANDRÉU, P.; CASUSO QUESADA, R. (2006) Arquitecto Berges (1891-1839). Jaén: Tinta Blanca Editor, 2006 CUEVA MATAS, J. (1991) El ensanche de Berges de 1927. Revista Senda de los Huertos, n² 23, 1991, pp. 71-84

GONZÁLEZ CORRAL, B. (2003) Arquitectura y urbanismo en papel del siglo XX, fondo Zuazo. En Actas del $5^{\circ}$ Congreso de Historia del Papel en España. Sarriá de Ter (Girona), 2-4 octubre de 2003, pp. 71-86

HAWTHORNE, N. (1851) The House of Seven Gables. A Romance. Boston: Ticknor, Reed and Fields, 1851

MATTEINI, M.; MOLES, A. (2001) La química en la restauración: los materiales del arte pictórico. Hondarribia: Nerea [2001]; [Sevilla]: Instituto Andaluz del Patrimonio Histórico, Consejería de Cultura

PÉREZ ESCOLANO, V. (1980) La arquitectura en Andalucía. En W. AA. LoS andaluces. Madrid: Itmo, 1980, pp. 349-357

SERRANO RIVAS, A.; BARBACHANO SAN MILLÁN, P. (1987) Conservación y restauración de mapas y planos, y sus reproducciones: un estudio del RAMP. París: Unesco, 1987

VIÑAS LUCAS, R. (1990) El papel vegetal: problemática y restauración. Revista PÁTINA, n 54, 1990

YATES, S. A. (1986) La conservación del papel de calcar del siglo XIX. The Paper Conservador, no 8 , pp. 20-39

Restauración del plano original del

Ensanche de Jaén de Luis Berges (1927)

Román Fernández-Baca Casares

Director del IAPH

Lorenzo Pérez del Campo

Jefe del Centro de Intervención del IAPH

\section{Equipo Técnico del IAPH}

Rocio Hermosín Miranda, restauradora. Departamento de Tratamiento. Centro de Intervención

Maria Campoy Naranjo, historiadora del arte. Departamento de Investigación. Centro de Intervención

Eugenio Fernández Ruiz, fotógrafo. Laboratorio de Medios Físicos de Examen no destructivos. Centro de Intervención

Lourdes Martín Garcia, química. Estudio de Análisis físico-químico.

Centro de Investigación

Marta Sameño Puerto, bióloga. Estudio de Análisis biológico. Centro de Investigación

Plácido González Martínez, arquitecto. Centro de Documentación y Estudios

Plazo de ejecución

Noviembre 2008 - marzo 2009 